\title{
The relationship of NM23 (NME) metastasis suppressor histidine phosphorylation to its nucleoside diphosphate kinase, histidine protein kinase and motility suppression activities
}

\author{
Imran Khan ${ }^{1}$ and Patricia S. Steeg ${ }^{1}$ \\ ${ }^{1}$ Women's Malignancies Branch, Center for Cancer Research, National Cancer Institute, Bethesda, MD, USA \\ Correspondence to: Imran Khan, email: imran.khan@nih.gov \\ Keywords: NM23; metastasis suppressor; tumor metastasis; kinase; histidine \\ Received: October 17, $2017 \quad$ Accepted: December 21, 2017 Published: December 31, 2017 \\ Copyright: Khan et al. This is an open-access article distributed under the terms of the Creative Commons Attribution License 3.0 (CC BY \\ 3.0), which permits unrestricted use, distribution, and reproduction in any medium, provided the original author and source are credited.
}

\section{ABSTRACT}

The NM23/NME gene was identified as a metastasis suppressor. It's reexpression inhibited cancer cell motility and suppressed metastasis, without effecting primary tumor size in multiple model systems. The mechanisms of NME suppression of motility and metastasis are incompletely known. Of particular interest, has been NME histidine 118 phosphorylation, involved in nucleoside diphosphate kinase (NDPK) and histidine protein kinase (HPK) activities. Using recently developed monoclonal antibodies to phosphohistidine, we have addressed the correlation of NME phosphohistidine with motility suppression, and distinguished the NDPK and HPK contributions. While general levels of NME correlated with its 1-phosphohistidine form in two cell line model systems, two exceptions were noted: Tumor cells actively migrating in scratch assays, even if expressing high levels of NME1, were low in its 1-phosphohistidine form. Site-directed mutagenesis of NME1 histidine 118 and proline 96 was examined by transfection experiments and partial purification of recombinant proteins. NME1 ${ }^{\text {P96s }}$ overexpressing tumor cells exhibited high motility and migration phenotypes despite high 1-phosphohistidine content and NDPK activity; HPK activity using succinate thiokinase as a substrate was poor. The data suggest the importance of NME 1-phosphohistidine levels in potential mechanistic pathways of metastasis suppression and point toward the HPK activity of NME1 downstream of autophosphorylation.

\section{INTRODUCTION}

The tumor metastatic process has defied therapeutic targeting, in part due to its intricate, dynamic regulatory pathways. Metastasis suppressor genes, genes that upon overexpression (or re-expression), significantly inhibit metastasis without effecting primary tumor size, constitute one avenue to dissect the metastatic process. Herein we focus on the NME/NM23 family of metastasis suppressor genes in one crucial component of metastasis, tumor cell motility in vitro. NME was credentialed by its reduced expression in highly metastatic melanoma cell lines as compared to equally tumorigenic, related, poorly metastatic melanoma cell lines [1]; overexpression in a variety of human and murine cancer cell lines reduced multi-organ metastasis without a significant effect on primary tumor size [2-12]. Simultaneously, a Drosophila form of NME, abnormal wing discs (AWD), was discovered, and controlled the differentiation of imaginal discs in larvae, linking development and metastasis [13]. A family of 10 NME genes have been identified in human [14].

The biochemical mechanism(s) of action of NME in tumor motility or metastasis suppression has been difficult to confirm, owing in part to its odd enzymatic activities, multiple binding partners and the presence of contaminants in some protein purifications. As far back as 1969, NME1 and -2 were reported to autophosphorylate on a histidine residue $[15,16]$. This phosphorylation was undetectable under standard SDS-PAGE conditions as it is acid and heat labile; other obstacles to its characterization included the need for orthophosphate labeling, the lack of commercially 
available phosphohistidine standards in chromatography, and a lack of an antibody to phosphohistidine. NME phosphohistidine contributes to two enzymatic activities: As a nucleoside diphosphate kinase (NDPK), NME reversibly removes the terminal phosphate of a nucleotide triphosphate, autophosphorylating on its own H118, and then transfers the phosphate to a donor nucleotide diphosphate [17-20]. Several pathways have been hypothesized to use the NME NDPK activity to suppress tumor motility and metastasis [21, 22]. As a histidine protein kinase (HPK), autophosphorylated NME transfers its phosphate to a substrate protein [23, 24]. For NME2, known substrates include $\beta$ subunit of heterotrimeric $G$ proteins $(\mathrm{G} \beta)$ [25], potassium channel KCa3.1 [26] and TRPV5 (a member of TRP channel family) [27, 28] and are all phosphorylated on a histidine residue. For NME1, in vitro assays demonstrated phosphorylation of histidine residues in substrate proteins including ATP citrate lyase and succinate thiokinase [29]. In addition, a NME1histidine to substrate serine phosphorylation was reported for the Kinase suppressor of ras (KSR) protein [30]; because of the difference in bond energies this transfer would be unidirectional. The NME1 HPK pathway has been correlated with tumor motility suppression [31]. Technical advances are required to make this research practicable. In addition to its enzymatic activities, NME proteins bind to a plethora of cellular proteins [32-36] that could contribute to metastasis suppression.

A remarkable advance in the field was recently reported, the development of monoclonal antibodies to N1phosphohistidine and N3-phosphohistidine by the Hunter lab [37]. In total cell lysate, NME was the predominate protein labeled with anti-N1-phosphohistidine [37]. With this tool and new protocols for western blots and staining, it is now possible to visualize 1-phosphohistidine NME and the relationship of NME 1-phosphohistidine to total NME, its enzymatic activities and regulation of tumor cell motility.

\section{RESULTS}

\section{NME suppression of in vitro motility in two model systems}

Two sets of vector and NME transfected cells were used to characterize NME phosphohistidine expression. MDA-MB-231T triple-negative breast cancer cells were transfected with Flag-tagged human NME1, NME2, murine Nme1 or an empty vector (V), and pools of Flagpositive cells were collected (Figure 1A). The vector transfectant expressed an almost undetectable level of NME protein, while the Flag tagged overexpressed proteins ran at a slightly higher molecular weight than endogenous NME. For a second model system, freshly thawed, previously reported vector (C-100) and NME1 (H1-177) transfectants of the MDA-MB-435 line [3] were used. Protein expression trends were similar to those originally published (Figure 1B).

\section{1-phosphohistidine levels in cell lysates}

NME was recognized as a 1-phosphohistidine containing protein based on initial discovery of an acid labile phosphorylation that was sequenced to its Histidine 118 [38, 39]. This histidine is mechanistically involved in two enzymatic activities, nucleoside diphosphate kinase (NDPK) and histidine protein kinase (HPK). The role of NME 1-phosphohistidine in NME biological suppression of tumor cell motility has remained largely unknown due to technical difficulties in working with phosphohistidine and an unexpected toxicity of H118 mutations in some overexpression experiments. A recently reported anti-N1phosphohistidine antibody provided a technical advance in this field, and reported that the major 1-phosphohistidine

A

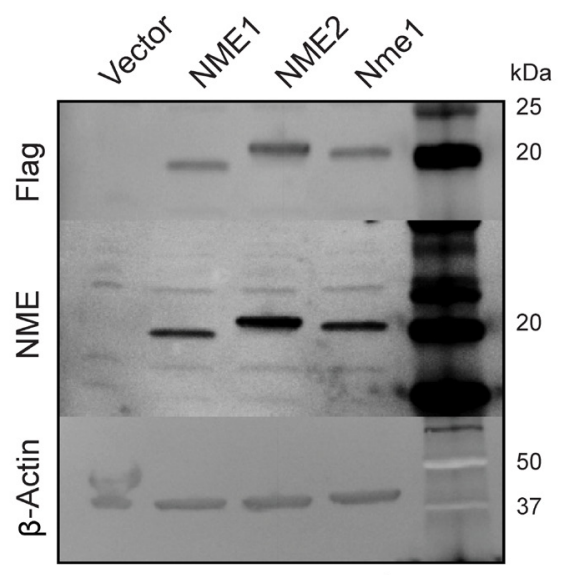

B

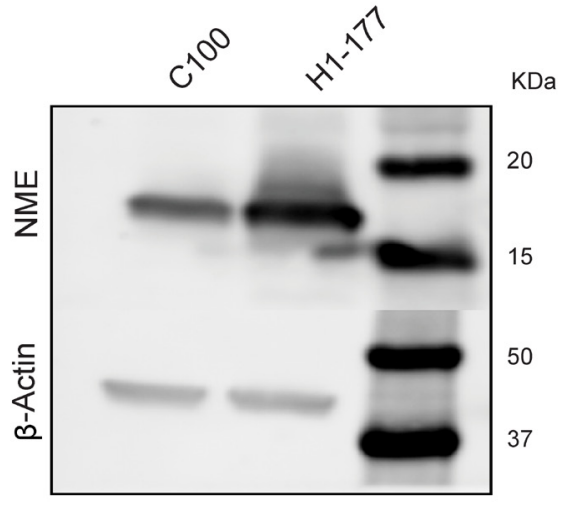

Figure 1: NME overexpression in two model systems. A. Human MDA-MB-231T breast cancer cells were transfected with either vector construct, Flag-tagged human NME1, NME2 or mouse ortholog Nme1, and their overexpression was confirmed by western blot. $\beta$-actin was used as loading control. B. Human MDA-MB-435 cells previously transfected with vector control (C100) or NME1 (H1-177), were subjected to western blot analysis using $\beta$-actin as loading control. 
expressing protein in cell lysates was NME [37]. Using anti-N1-phosphohistidine antibody, we asked if the 1-phosphohistidine content of cell lysates paralleled total NME protein levels. NME 1-phosphohistidine levels were quantified using a modified cell lysate and SDSPAGE protocol at basic $\mathrm{pH}$ and without heating. As a control, samples were split and one half was heated, as 1-phosphohistidine is heat labile [37]. Figure 2A shows a 1-phosphohistidine blot of the MDA-MB-231T transfectants. NME proteins ran as a doublet of NME1 and -2. Overexpression of any NME protein in the MDAMB-231T model system was accompanied by increased NME 1-phosphohistidine. Overexpression of NME1 is known to transphosphorylate NME2 and therefore
A

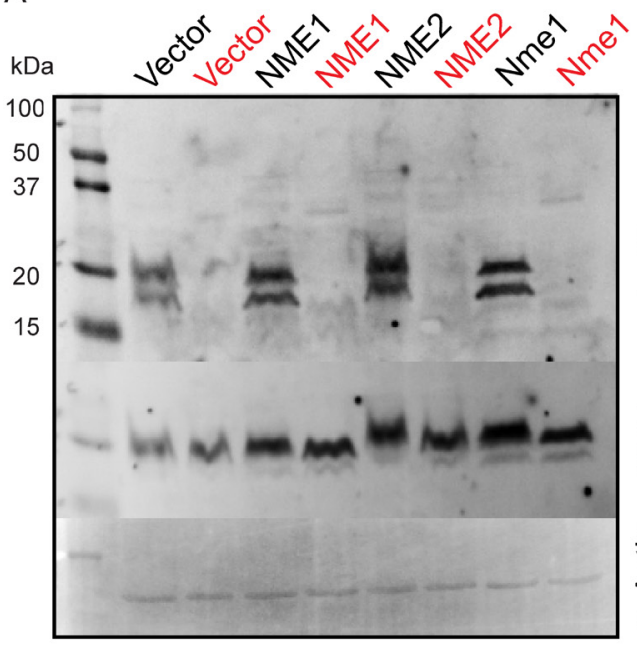

B

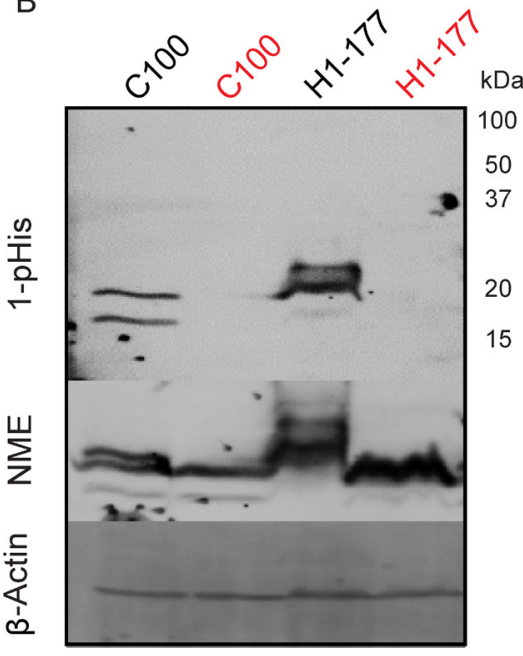

C

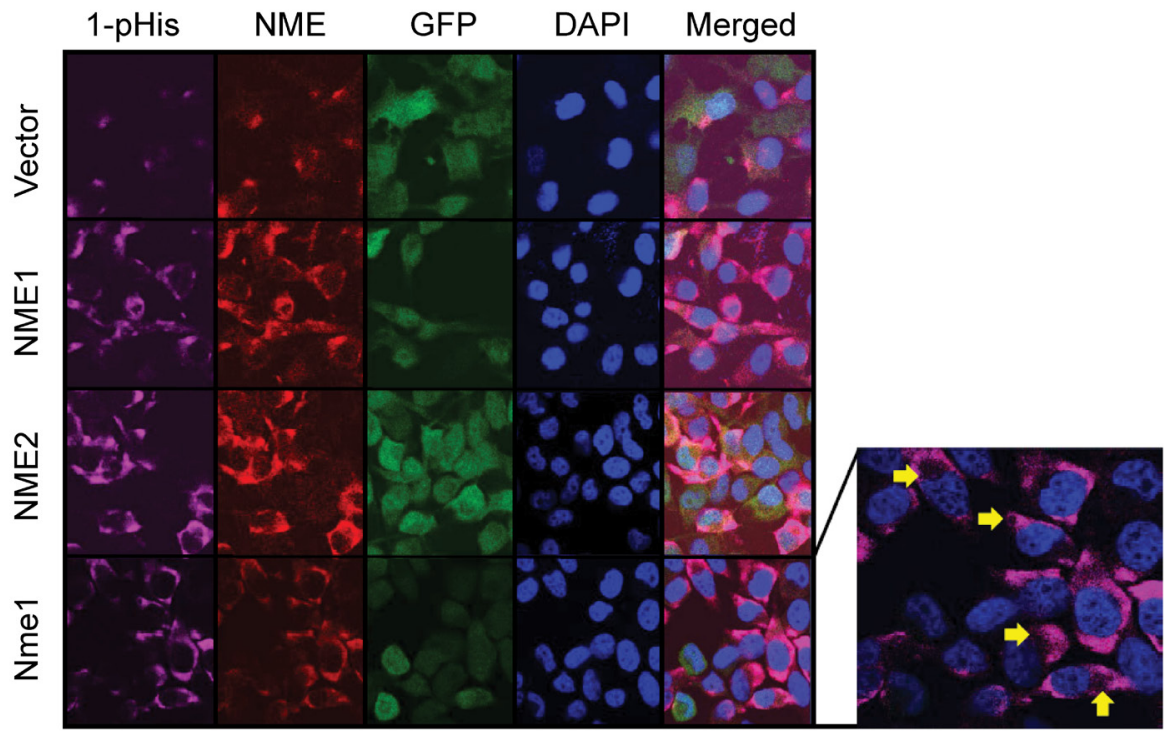

Figure 2: Correlation of total and 1-phosphohitidine NME level in cell lysates. A. Cell lysates prepared from vector and NME overexpression (NME1, NME2 or mouse ortholog Nme1) in MDA-MB-231T cells were assessed for 1-phosphohistidine (1-pHis) level using anti-N1-phosphohistidine antibody on a basic gel with no heating. For specificity, replicate samples were heated at $95^{\circ} \mathrm{C}$ for 10 min and loaded next to each sample (red). B. MDA-MB-435 cells lysates from vector (C100) and NME overexpression (H1-177) were also assessed for 1-pHis in similar manner. Following stripping, both blots were re-probed with total NME and $\beta$-actin antibodies. C. For immunofluorescence, MDA-MB-231T cells with GFP co-expressing vector or NME overexpression were fixed in PFA and stained for 1-pHis using anti-N1-phosphohistidine antibody. Following 1-pHis primary incubation, cells were washed twice and were then stained with total NME1/2 antibody. Nuclei were visualized using DAPI (Blue). Images were captured at $65 x$ magnification. Yellow arrows indicate vacuoles in 1-pHis staining highlighting acidic compartments. 
A

C

E

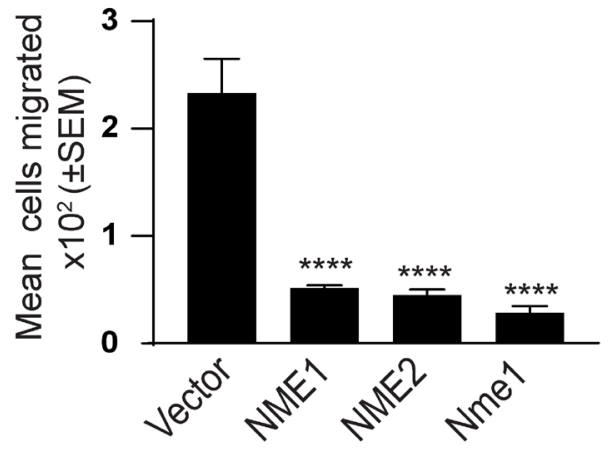

B

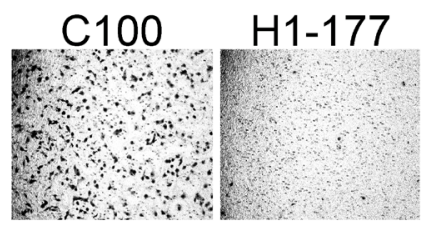

D

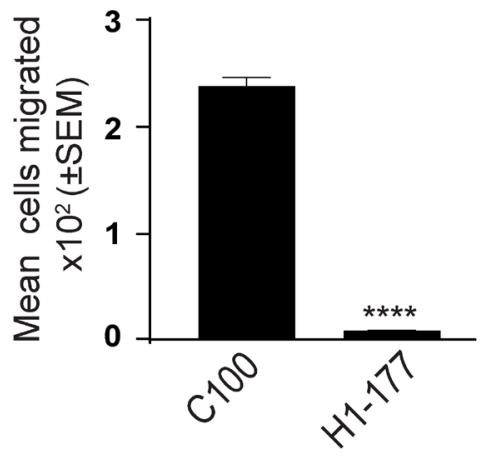

F

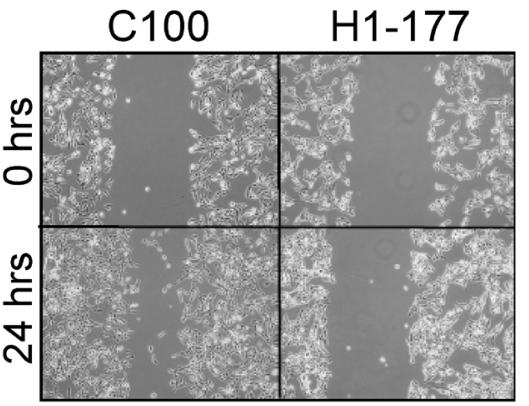

$\mathrm{H}$

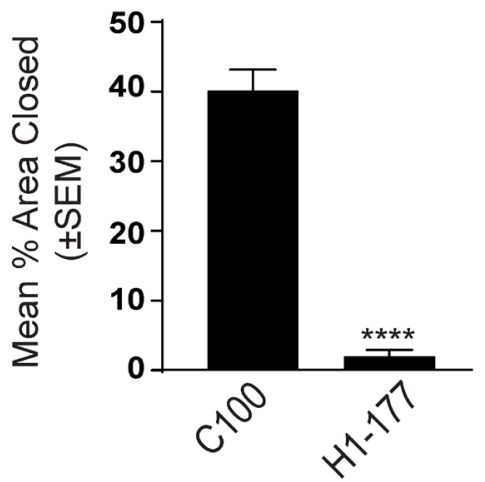

Figure 3: NME overexpression suppresses in vitro motility and migration. NME overexpressing MDA-MB-231T (A, C, E, G) and MDA-MB-435 (B, D, F, H) cells were assessed for motility (A-D) and migration (E-H). A-D. Cells were permitted to migrate through a bovine collagen type I-coated $8 \mu \mathrm{m}$ membrane toward the chemoattractant $(1 \% \mathrm{FBS})$ in a Boyden chamber. Cells migrated through membrane were photographed (A, B) and the mean number of cells migrated was quantitated using ImageJ (C, D). E-H. Cells were plated in 6-well plates and cultured for $24 \mathrm{hrs}$. A line was scratched with a 200- $\mu \mathrm{m}$ pipette tip and migration of cells into the scratch was photographed after $24 \mathrm{hrs}(\mathrm{E}, \mathrm{F})$. Percent area open was quantitated using ImageJ $(\mathrm{G}, \mathrm{H})$. All experiments shown are representative of 4 replicates performed $(* P<0.05$, ** $P<0.01$, *** $P<0.001$, **** $P<0.001)$. 
1-pHis intensity of both the doublet bands increased with NME1 overexpression. The blot was re-incubated with antibody to total NME and then $\beta$-actin as a loading control. Total NME protein, but not 1-phosphohistidine, was observed in heat treated samples, confirming the heat labile nature of the 1-phosphohistidine moiety. A similar experimental approach with MDA-MB-435 transfectants demonstrated similar trends (Figure 2B). As histidine can also become phosphorylated at N3 position, we assessed if NME became N3 phosphorylated using antiN3-phosphohistidine antibody. No 3-phosphohistidine (3pHis) band was detected in NME proteins (Supplementary Figure 1).

\section{NME and 1-phosphohistidine in cell cultures}

Fuhs et al. also reported the use of the 1-phosphohistidine antibody for immunofluorescence staining [37]. As NME was by far the brightest 1-phosphohistidine band in total cellular lysates (Figure 2A-2B), it was reasonable to image total 1-phosphohistidine expression. Using a modified immunofluorescence protocol (all basic buffers, $\mathrm{pH}$ 9), total 1-phosphohistidine NME was compared to total NME (Figure 2C). Total NME in the vector transfectants was mostly cytoplasmic and concentrated in a few foci either near the cell surface or perinuclearly; 1-phosphohistidine was even more restricted than total NME, but overlapping its areas of greatest intensity. When any form of NME was overexpressed, cells exhibited heterogeneity in overall cellular levels and subcellular distribution of NME; 1-phosphohistidine levels also overlapped areas of greatest NME intensity. Small circular subcellular compartments were observed that could be acidic lysosomes (arrows). The specificity of 1-phosphohistidine immunostaining was demonstrated by incubating the slides in boiling citrate buffer for 10 min prior to staining, leading to loss of 1-phosphohistidine staining specifically (Supplementary Figure 2). Under standard culture conditions 1-phosphohistidine levels generally correlated with total NME expression.

\section{Correlation with NDPK activity and motility}

One of the key in vitro correlates of NME function is suppression of tumor cell motility [40]. Using the combination of factors in fetal bovine serum (FBS) as an attractant, overexpression of NME significantly reduced motility in Boyden chamber assays (Figure 3A-3D) and migration in scratch assays (Figure $3 \mathrm{E}-3 \mathrm{H}$ ). No effect was observed on proliferation (Figure 4A, 4B).

The NDPK activity of cell lysates was quantified by a spectrophotometric assay for the formation of NAD (oxidized) from NADH (reduced) leading to the loss of OD at $340 \mathrm{~nm}$ (Figure 4C, 4D, time courses on
Supplementary Figure 3A-3C), When total cellular NDPK activity was quantified, 1-phosphohistidine and total NME levels were correlated with NDPK activity (Figure 4C, 4D). In cultures, 1-phosphohistidine expression paralleled total NME and NDPK activity, and was inversely related to tumor cell motility.

\section{Actively migrating tumor cells}

Cellular NME and 1-phosphohistidine levels were compared in migrating versus static conditions. Vector and NME1 transfected MDA-MB-231T and MDA-MB-435 cells were cultured in scratch assays as previously shown. Cells actively migrating in the scratch were compared to the mostly confluent monolayer distant from the scratch for total NME protein and 1-phosphohistidine (Figure $5 \mathrm{~A}, 5 \mathrm{~B}$ and Figure 6A, 6B). For the vector MDA-MB$231 \mathrm{~T}$ transfectants, only occasional NME-positive cells were observed in either the scratch or confluent areas, and co-localized with 1-phosphohistidine. Upon enforced overexpression of NME1, total NME protein was higher in nonmotile and the few migrating cells. However, the 1-phosphohistidine level of the migrating NME overexpressing cells was comparable to that of the vector transfectants (Figure 5C, 5D). Nonmigrating NME overexpressing cells exhibited elevated 1-phosphohistidine levels consistent with data from cultures (Figure 2C). Similar trends were observed in MDA-MB-435 cells (Figure 6C, 6D). The data suggest that NME 1 -phosphohistidine levels are regulated in tumor cell migration, and that total NME and its 1-phosphohistidine form are not correlated in active motility.

\section{NME mutations}

To further explore the relationship of NME protein with its 1-phosphohistidine form, enzymatic activity and tumor cell motility, a series of previously reported NME mutations were re-derived in MDA-MB-231T cells. Histidine 118 is the site of NME autophosphorylation, and the $\mathrm{H} 118 \mathrm{~F}$ transfectants in the originally published MDA-MB-435 cell line failed to show NDPK or HPK activity above vector controls [41]. P96 is located on a loop structure of NME and is known as the killer of prune mutation due to its lethal interaction with the Drosophila prune gene [42-44]. Based on crystal structure and developmental studies in Drosophila, it is speculated that P96S mutation causes a change in NME conformation which possibly affects its binding partners or oligomerization leading to compromised/partial function. A NME1 ${ }^{\text {P96S }}$ mutant transfectant in MDA-MB-435 cells was deficient in ice bucket HPK assays [31, 41, 45] but had NDPK activity consistent with wild type NME overexpression [41].

MDA-MB-231T cells expressing a vector, wild type 
NME1 or its P96S or H118F (NME1 ${ }^{\mathrm{P} 96 \mathrm{~S}}$ and NME1 $1^{\mathrm{H} 118 \mathrm{~F}}$ ) mutations were prepared (Figure 7A, unheated samples). The 1-phosphohistidine levels of the transfectants is also shown on Figure 7A. NME overexpressing cells showed greater 1-phosphohistidine expression than vector controls as expected (Figure 7A and quantitation on Supplementary Figure 4A). The histidine mutant overexpressing cells exhibited 1-phosphohistidine levels approximating the vector transfectants, confirming the specificity of the antibody (Supplementary Figure 4A). The P96S transfectants exhibited 1-phosphohistidine levels comparable to wild type NME1 transfectants (Figure 7A and Supplementary Figure 4A). 1-phosphohistidine was heat sensitive (Figure 7A). Similar results were obtained for the level of 1-phosphohistidine and NME using immunofluorescence in NME wild type and mutants (Figure 7B and Supplementary Figure 4B, 4C). In vitro motility in Boyden chambers and migration in scratch assays are shown in Figure 7C-7F. Wild type NME overexpression significantly suppressed tumor cell motility $(\sim 80 \%)$ and migration $(50 \%)$. For H118F overexpressing cells, a $28 \%$ diminution of motility to FBS was observed that was not statistically significant, and no decrease in migration was noted as compared to wild type NME1 in scratch assays (12\%). The P96S mutant NME1 overexpressing cells were motility and migration competent at levels almost identical to vector control. The NDPK activity of the cell lysates paralleled NME1
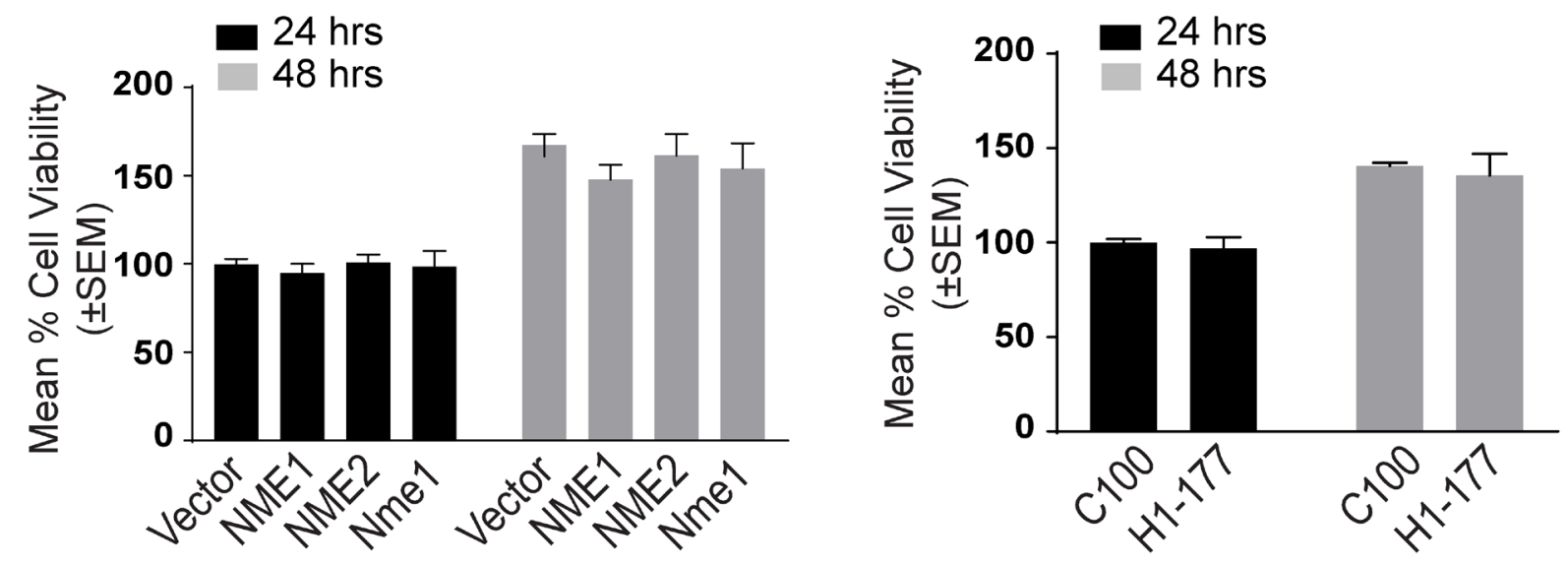

C
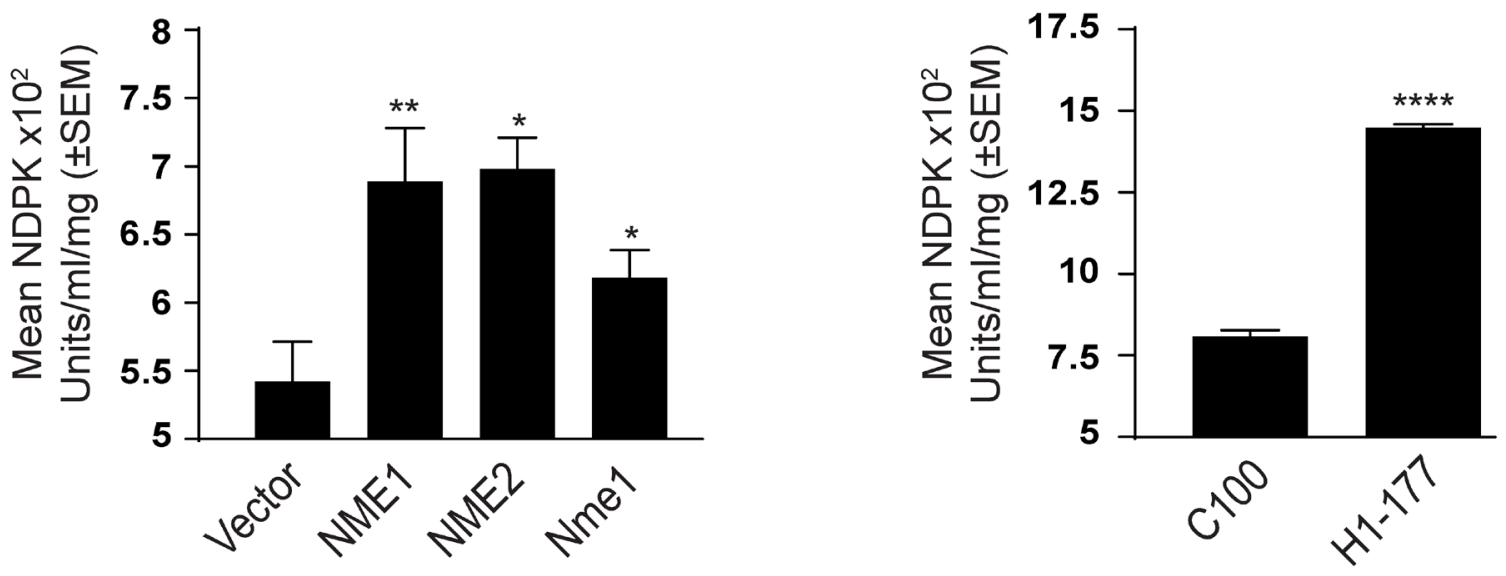

Figure 4: Characterization of NME transfectants. Proliferation of NME overexpressing MDA-MB-231T A. and MDA-MB-435 cells B. after 24 and 48 hrs was assessed using AlamarBlue dye. The NDPK activity of NME overexpressing MDA-MB-231T C. and MDAMB-435 D. cell lysates was quantified by a spectrophotometric assay for the formation of NAD (oxidized) from NADH (reduced) leading to the loss of OD at $340 \mathrm{~nm}$. All experiments are representative of 4 replicates conducted. 
1-phosphohistidine levels (Figure 7G). In summary, these data revealed a discrepancy between 1-phosphohistidine NME1 levels and biological function: P96S NME1 overexpressing cells exhibited high 1-phosphohistidine levels yet were motility competent.

To further examine the relationship of NME1 mutations to enzymatic activities, recombinant NME wild type, P96S and $\mathrm{H} 118 \mathrm{~F}$ constructs were His tagged, expressed in E. coli and partially purified by affinity purification using immobilized metal affinity chromatography. Figure 8A shows a coomassie stained $10-20 \%$ gradient SDS-PAGE gel of the partially purified proteins. All proteins formed hexamers on native PAGE gel (Supplementary Figure 5) [46-48]. In Figure 8B the relationship of NME1 1-phosphohisitidine to its NDPK and HPK activities is outlined. A phosphate, via a high energy phosphohistidine bond on NME1, is transferred reversibly to either nucleotide diphosphate in NDPK or

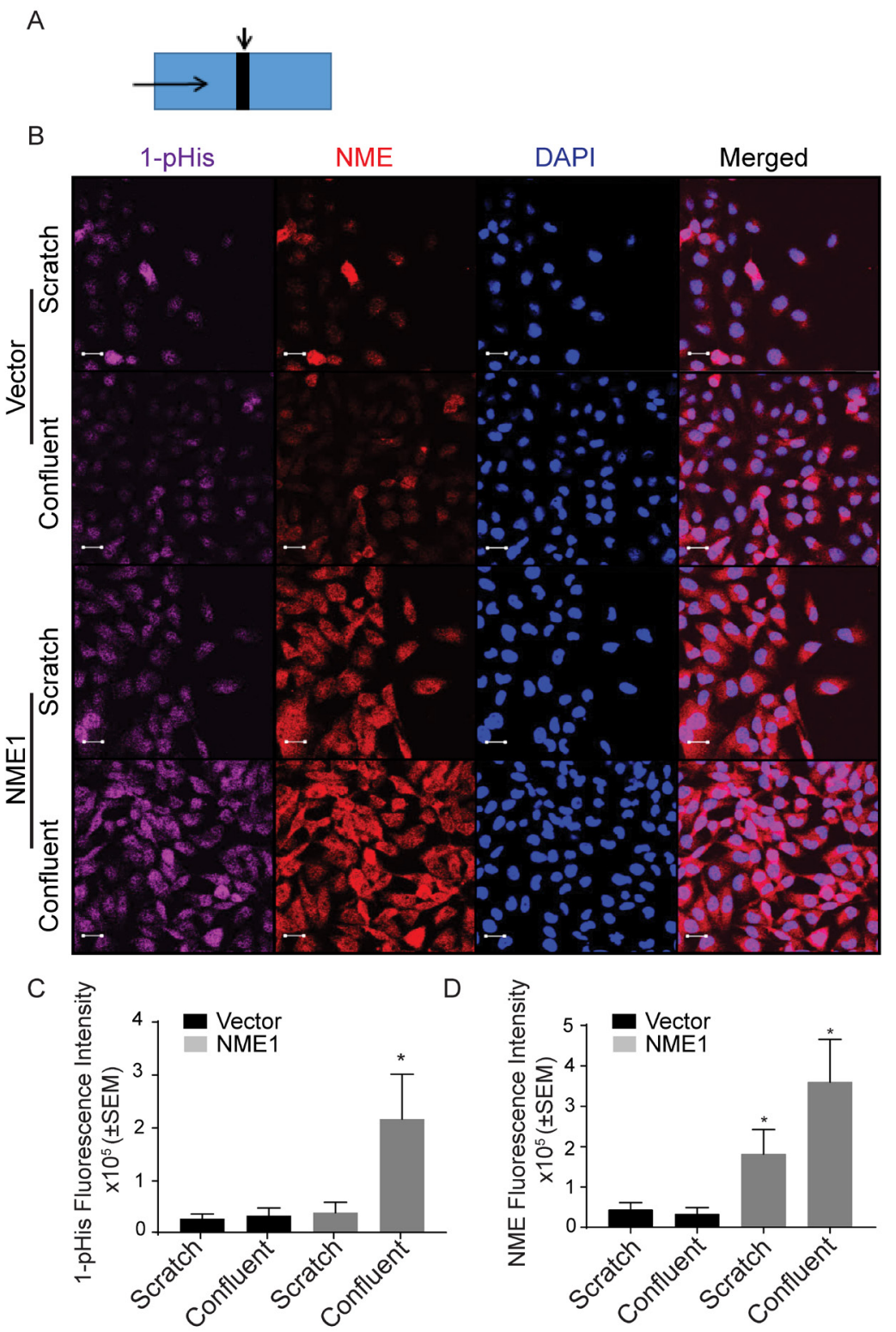

Figure 5: MDA-MB-231T migrating cells have low 1-phosphohistidine level regardless of total NME level. Vector and NME overexpressing MDA-MB-231T cells were plated in chamber slides and cultured for $24 \mathrm{hrs}$. A. Schematic of culture. A line was scratched with a $200-\mu \mathrm{m}$ pipette tip (Scratch is indicated by a downward arrow and movement of cells are indicated by horizontal arrow). Cells were permitted to migrate into the scratch for $24 \mathrm{hrs}$, while confluent cells distant from scratch remained nonmotile. B. After 24 hrs cells were fixed in PFA and immunofluorescence was performed for 1-phosphohistidine (1-pHis) and total NME1/2. Immunofluorescence staining was quantitated as total fluorescence intensity of 1-phosphohistidine (1-pHis) C. and total NME D. NME overexpressing cells in the scratch area did not exhibit strong 1-pHis positivity. Nuclei were visualized using DAPI (Blue). Images were captured at $65 \mathrm{x}$ magnification in the scratch and adjacent (confluent) area. Student's test was performed between Vector-Scratch $v s$ NME-Scratch and Vector-Confluent vs NME-Confluent. 
to a protein in HPK activity. The NDPK activity of the recombinant proteins was determined (Figure $8 \mathrm{C}$ ) and trends matched that of the transfected MDA-MB-231T cell lysates (Figure 7G).

One of the clearest HPK substrates reported for NME1 in vitro is succinate thiokinase (Succinyl coenzyme A synthetase or Succinate-CoA ligase), as it is incapable of a histidine autophosphorylation [29]. Two succinate thiokinase forms are now recognized, alpha (SUCLG1) and beta (SUCLG2), which were obtained in partially purified form commercially. For the HPK assay, succinate thiokinase was incubated with recombinant NME1 and ATP as a triphosphate source; the resulting mixtures were resolved on a basic gel and probed for total and 1-phosphohistidine proteins (Figure 8D, left panel). For SUCLG2, a faint band at $70 \mathrm{kDa}$, the expected

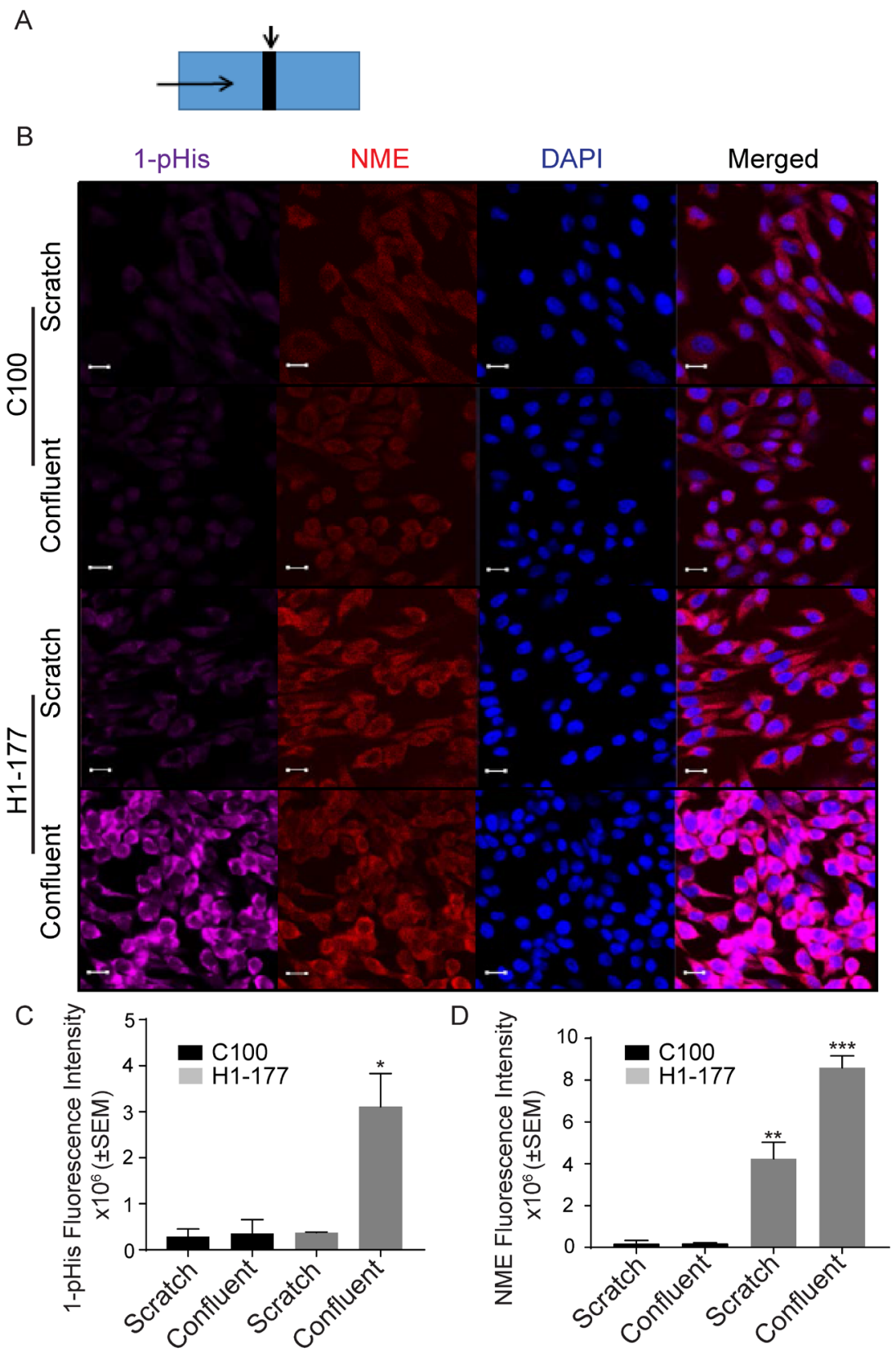

Figure 6: MDA-MB-435 migrating cells have a low 1-phosphohistidine level that does not correlate with total NME level. A. Vector (C100) and NME1 (H1-177) overexpressing MDA-MB-435 cells were plated in chamber slides and treated as described in the legend for Figure 5A. B. After $24 \mathrm{hrs}$ cells were fixed in PFA and immunofluorescence was performed for 1-pHis and NME1/2. Immunofluorescence staining was quantitated as total fluorescence intensity of 1-phosphohistidine (1-pHis) C. and total NME D. Both vector (C100) and NME overexpressing cells (H1-177) in the scratch area did not exhibit strong 1-pHis positivity. Nuclei were visualized using DAPI (Blue). Images were captured at $65 \mathrm{x}$ magnification in the scratch and confluent areas. Student's t-test was performed between Vector-Scratch vs NME-Scratch and Vector-Confluent vs NME-Confluent. 

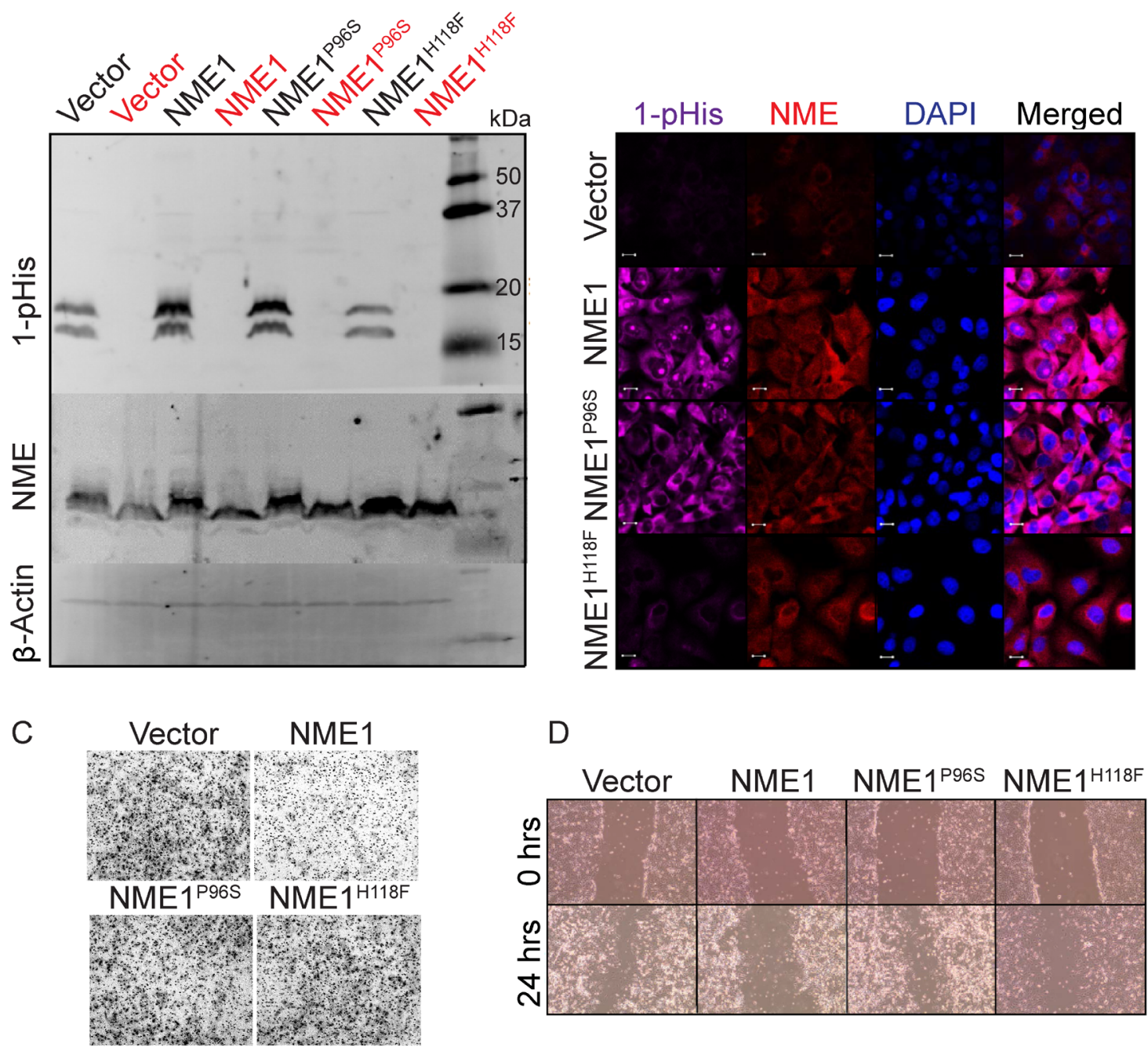

$\mathrm{D}$
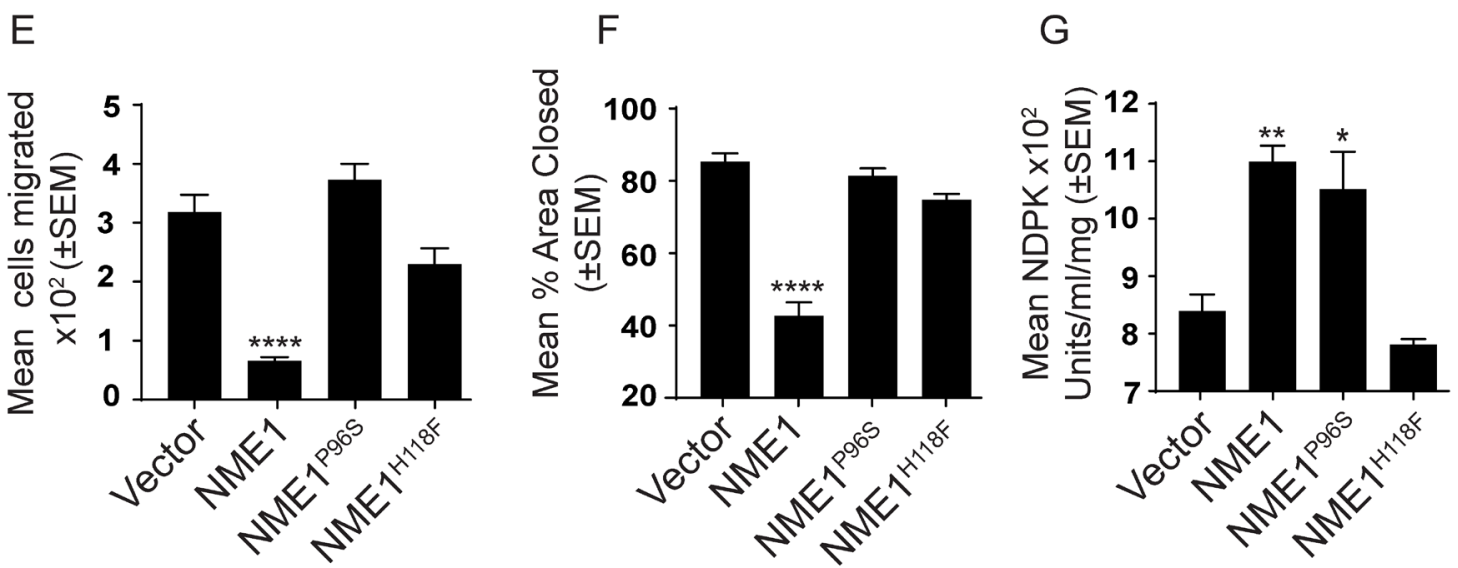

Figure 7: The NME ${ }^{\mathrm{P} 9 \mathrm{~S}}$ site directed mutant distinguishes 1-pHis and NDPK activities from suppression of motility in vitro. A. MDA-MB-231T cells stably expressing a vector, wild type NME1 or its P96S or H118F (NME1 ${ }^{\mathrm{P} 96 \mathrm{~S}}$ and $\mathrm{NME} 1^{\mathrm{H} 118 \mathrm{~F}}$ ) mutations were lysed and assessed for 1-pHis levels. Lysates were split into two, and one sample was heated (red). Blots were re-probed for NME1/2 and $\beta$-actin. B. 1-pHis and NME expression was also assessed by immunofluorescence in the above cells. Nuclei were visualized using DAPI (Blue). Images were captured at 65x magnification. C. Cells were tested for motility in Boyden chamber assay using $1 \%$ FBS as chemoattractant and motility quantitated E. D. Cells were tested for migration in scratch assay in $0.2 \%$ serum and migration quantitated $\mathbf{F}$. G. The NDPK activity of lysates was quantitated using spectrophotometric assay. All experiments are representative of 4 replicates $(* P<$ $0.05, * * P<0.01, * * * P<0.001, * * * * P<0.001)$. 
A

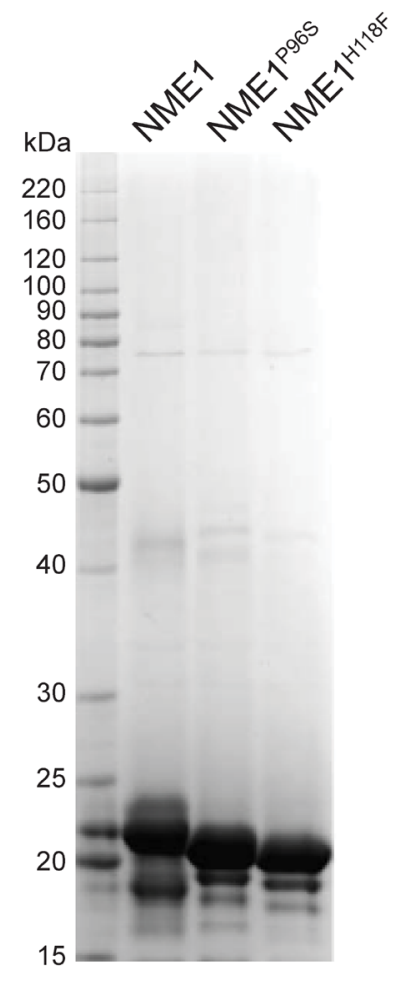

B

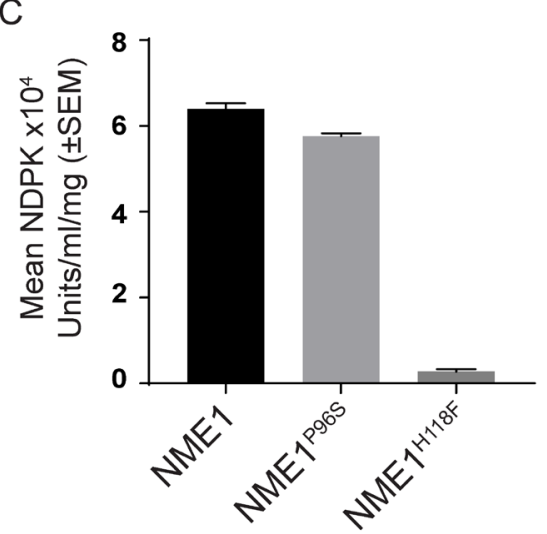

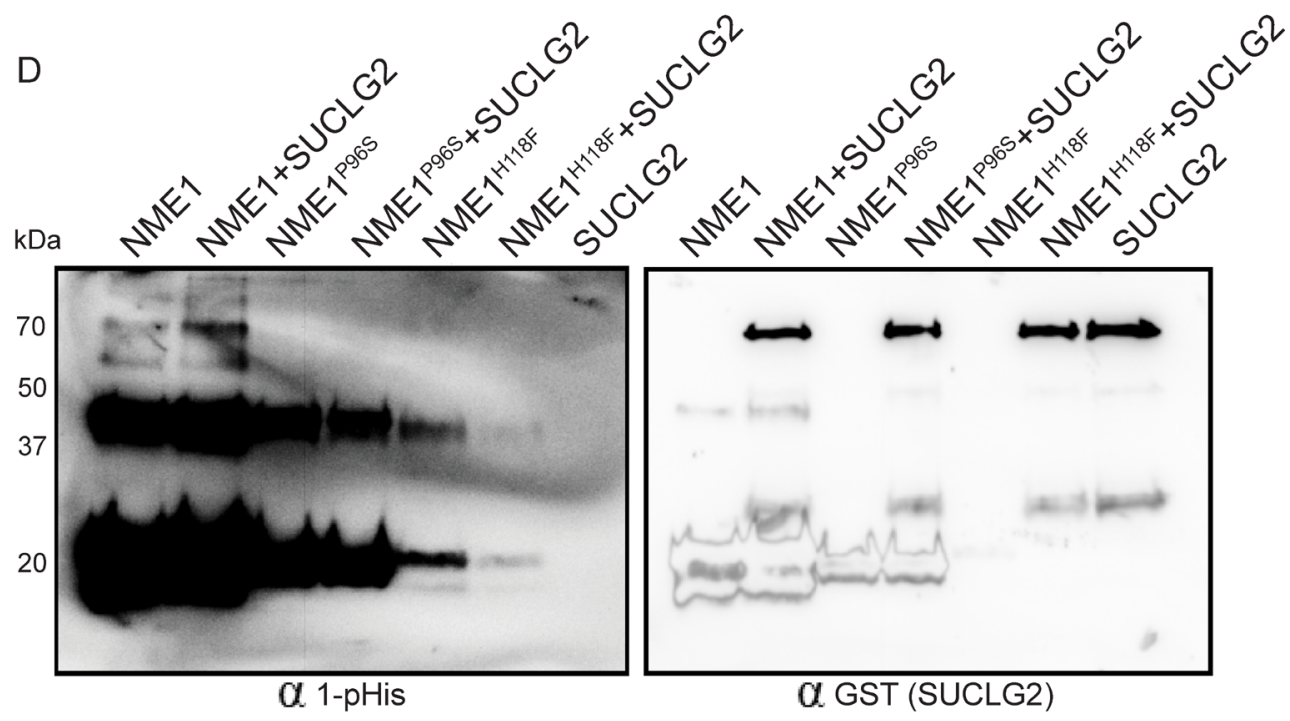

Figure 8: NME1 ${ }^{\mathrm{P} 96 \mathrm{~S}}$ recombinant protein provides a correlation of HPK activity with motility suppression. A. Recombinant $\mathrm{NME} 1, \mathrm{NME} 1^{\mathrm{P} 96 \mathrm{~S}}$ and $\mathrm{NME} 1^{\mathrm{H} 18 \mathrm{~F}}$ constructs were His tagged, expressed in $E$. coli and partially purified by affinity purification using immobilized metal affinity chromatography. A coomassie stained 10-20\% gradient SDS-PAGE gel of the partially purified proteins is shown. B. Diagrammatic representation of NME activities; NME1 is reversibly auto-histidine phosphorylated (H118) in presence of ATP. This phosphate, via a high energy phosphohistidine bond on NME1, is transferred reversibly to either a nucleotide diphosphate in NDPK activity or to a protein in HPK activity. C. The proteins were assessed for their NDPK activity by a spectrophotometric assay. D. The proteins were assessed for their HPK activity using SUCLG2 as their substrate. NME1, NME1 ${ }^{\mathrm{P} 96 \mathrm{~S}}$ or NME1 ${ }^{\mathrm{H} 118 \mathrm{~F}}(400 \mathrm{ng})$ were incubated with SUCLG2 (600 ng) in TMD buffer containing ATP for 30' at room temperature. Reaction was stopped by adding 5x lysis buffer and 1-phosphohistidine western protocol was used for the detection of 1-pHis; after stripping, SUCLG2 (GST tagged) was detected by antiGST antibody. Histidine phosphorylated SUCLG2 appears in NME1+SUCLG2 lane at $\sim 70 \mathrm{kDa}$. 1-pHis band at $\sim 20 \mathrm{kDa}$ and $\sim 37 \mathrm{kDa}$ are histidine phosphorylated monomer and dimer of NME1. 
size of SUCLG2, was repeatedly observed in a reaction containing NME1 without added SUCLG2. Reprobing of the blot with anti-GST (SUCLG2) demonstrated that this was not recombinant succinate thiokinase (right panel). Importantly, the level of 1-phosphohistidine was increased at $70 \mathrm{kDa}$ with addition of SUCLG2, indicative of NME1 HPK activity. Neither the NME1 ${ }^{\mathrm{P} 96 \mathrm{~S}}$ nor NME $1^{\mathrm{H} 118 \mathrm{~F}}$ recombinant proteins exhibited HPK activity to SUCLG2. Several controls further clarify the HPK assay: The recombinant SUCLG2-only lane in the right panel blot confirmed the mobility of this protein on the blot. A lack of any band in the left panel shows SUCLG2 has no autokinase activity. SUCLG1 was also tested as a possible substrate of NME1, however no increase in 1-phosphohistidine band ( 70KD) could be seen with NME1 or in both mutants (Supplementary Figure 6A, B). As an additional control, 1-pHis blots of SUCLG1 and SUCLG2 were stripped and reprobed with NME antibody. NME1 predominantly formed monomers ( $20 \mathrm{kDa})$ and dimers $(\sim 40 \mathrm{kDa})$, and did not form any oligomeric structures at $70 \mathrm{kDa}$ which could overlap the 1-pHis band of SUCLG2 (Supplementary Figure 7). Similarly, a control gel with and without ATP for 1-pHis demonstrated that, without ATP, both NME1 and NME1 ${ }^{\mathrm{P} 96 \mathrm{~S}}$ did not autophosphorylate on 1-pHis (Supplementary Figure 8); NME1 $1^{\mathrm{H} 118 \mathrm{~F}}$ had no autophosphorylation with or without ATP (a very faint band could be endogenous wild type contamination). NME1 was also tested for HPK activity at the N3-histidine of both SUCLG1 and SUCLG2. No detectable phosphotransfer at 3-pHis occurred (Supplementary Figure 9). SUCLG2, being a substrate of NME HPK activity on 1-pHis, was also tested for phosphotransfer on other amino acids such as serine, threonine and tyrosine. No increase in phosphoserine, (Supplementary Figure 10A), phosphothreonine (Supplementary Figure 10B) or phosphotyrosine, (Supplementary Figure 11) was observed, with only autophosphorylation bands were visible.

Taken together, comparison of wild type and P96S NME1 proteins with in vitro motility suppression and enzymatic activities shows a clear disconnect. $\mathrm{NME}^{\mathrm{P} 96 \mathrm{~S}}$ 1-phosphohistidine levels agreed with total NME1 levels and NDPK activity, but were deficient in HPK activity and suppression of tumor cell motility. The data suggest that the $\mathrm{NME}^{\mathrm{P} 96 \mathrm{~S}}$ deficiency lies downstream of NME H118 autophosphorylation, possibly phosphorylation of key substrates needed for NME1 mediated motility suppression.

\section{DISCUSSION}

A molecular understanding of the mechanistic pathways mediating tumor metastasis may lead to new therapies. The metastasis suppressor gene field may make original contributions to this field, as they function specifically in metastases and not in primary tumor growth (rev. in [49-51]). Of the many metastasis suppressor proteins and miRNAs, few have fully elucidated their mechanism(s) of action. The current work builds on a voluminous but inconclusive history of potential mechanistic pathways for metastasis suppression by the NME (NM23, nucleoside diphosphate kinase, AWD) family. Considerable evidence indicates that protein:protein interactions with NME modulate components of the metastatic process and in vivo metastasis ([52-54] as examples). The role of NME enzymatic activities has been less certain. Roles for the NME NDPK activity in the provision of certain nucleotides have been reported to contribute to dynamin function [55], oxidative stress [56], and endothelial contractility [57]. The NDPK activity of NME is not the only enzymatic activity emanating from its histidine 118 autophosphorylation, NME can also serve as a HPK. Histidine phosphorylated proteins may represent $6 \%$ of total protein phosphorylation in eukaryotes [58]. Recent data suggest that phosphohistidine status may influence the stability and activity of the EGFR receptor tyrosine kinase in the cancer microenvironment [59]. HPKs are poorly understood for technical reasons. The HPKs differ from well-studied kinases in that they form an autophosphorylated intermediate, histidine 118 in NME. This pathway has been best validated for NME2 in noncancer signaling including the beta subunit of G-proteins [60] and lymphocytic potassium channels [26]. Our work in the 1990s with Dr. Paul Wagner identified ATP citrate lyase [23], aldolase C [45], NME2 and succinic thiokinase [31] as in vitro HPK substrates of NME1 (although NME2 was likely bound), and limited mutational analysis suggested that this pathway may correlate with motility suppression. Progress in confirming these pathways and identifying metastasisrelevant substrates was impossible due to the acid and heat lability of the phosphohistidine bond, making even SDS-PAGE impossible. This field reopened in 2014 with the publication of monoclonal antibodies to 1- and 3-phosphohistidine, and methods for their use. NME1 and NME2 were the most prominent 1-phosphohistidine proteins in mammalian cell lysates [37]. We present herein the first analysis of NME 1-phosphohistidine expression in tumor cell motility.

In a comparison of vector and NME overexpressing transfectants of two cancer cell lines NME total protein often directly correlated with levels of NME 1-phosphohistidine observed on modified western blots or total 1-phosphohistidine in immunofluorescence staining. Controls established the heat and acid lability of 1-phosphohistidine and a lack of 3-phosphohistidine in agreement with the data of Fuhs et al. By immunofluorescence, 1-phosphohistidine staining overlapped areas of most intense NME staining. It should be noted that this staining could include multiple NME family members and other minor histidine phosphorylated 
proteins. This difference may suggest that only a portion of NME is histidine phosphorylated or may result from differences in the sensitivity of the two antibodies. There is no evidence for 1-phoshohistidine NME being limited to a particular cellular compartment. Two discordances were observed in 1-phosphohistidine NME and selected endpoints that were of greatest interest. The first was in immunofluorescence of actively migrating MDA-MB$231 \mathrm{~T}$ cells in a scratch assay. Cells overexpressing total NME1 protein, that were migrating in the scratch area of a culture, were low in 1-phosphohistidine, comparable to vector transfectants, while nonmotile NME1 overexpressing cells away from the scratch in the same culture exhibited higher 1-phosphohistidine levels. This trend was observed in both MDA-MB-231T and MDAMB-435 models. The trend was most stark in the latter model which may reflect the facts that overexpression of NME was higher, and that it was a clonal and not mixed population of transfectants. Thus, as cells overcome high NME1 expression and become motile, their histidine phosphorylation is decreased, suggesting less downstream NDPK or HPK activity.

A second discordance arose in the comparison of vector, wild type NME1 and NME1 ${ }^{\mathrm{P} 96 \mathrm{~S}}$ transfectants. Both cell lysates and partially purified recombinant proteins were examined. By western blots, the NME1 ${ }^{\mathrm{P} 96 \mathrm{~S}}$ transfectant exhibited high total and 1-phosphohistidine NME levels, comparable to the wild type protein. Similar data were observed in recombinant proteins. Both the lysates and recombinant proteins of the P96S transfectant exhibited high NDPK activity, consistent with wild type NME overexpression. Yet, the NME1 ${ }^{\mathrm{P} 96 \mathrm{~S}}$ transfectants did not suppress motility or migration in vitro, a discordancy of total and 1-phoshohistidine NME with motility suppression. A hypothesis to explain this apparent discrepancy would be that the HPK activity of NME, downstream of its autophosphorylation, was mechanistically involved in motility suppression. A HPK assay was set up using the anti-1-phosphohistidine antibody and partially purified recombinant NME proteins. Given our reliance on NME1, due to a literature on tumor motility suppression and site-directed mutagenesis, we chose a NME1 HPK substrate, succinic thiokinase, as it fails to histidine autophosphorylate in vitro. The SUCLG2 and not SUCLG1 form was histidine phosphorylated by wild type NME. SUCLG2 contains only one histidine at position 105, which would be the site of phosphorylation. Both the P96S and H118F mutant NME proteins were unable to kinase SUCLG2 in vitro. The data support the hypothesis that the HPK activity of NME1 is mechanistically linked to its motility suppressive capacity. The P96S mutation likely affects a part of the HPK activity downstream of autophosphorylation such as interaction with and phosphate transfer to the substrate. With these data, it will be of interest to identify the potential physiological substrates of NME1 as a HPK.
Fuh et al. identified 630 histidine phosphorylated proteins by a modified mass spec methology, which could be substrates for NME1 [37]. In addition, it is possible that some of the many binding partners of NME1 may also be substrates. Another potential explanation for the data is that the 1-phosphohistidine form of NME1 has altered protein:protein binding activities, also affected by the P96S mutation. Further work is aimed at confirming a role for these activities in metastasis in vivo, and in other published biological processes such as development [61, $62]$.

\section{MATERIALS AND METHODS}

\section{Cell culture conditions and treatments}

Human triple negative breast cancer cell line MDAMB-231T (A subline of human MDA-MB-231 cells, generously provided by Dr. Zach Howard [63], Laboratory of Immunoregulation, National Cancer Institute, Bethesda, MD) and MDA-MB-435 tumor cells were cultured in Dulbecco's Modified Eagle Medium (DMEM) (Invitrogen, Grand Island, NY) supplemented with 10\% FBS in a humidified $37^{\circ} \mathrm{C}$ incubator at $5 \% \mathrm{CO}_{2}$. MDAMB-231T cells have been authenticated by our laboratory to the ATCC MDA-MB-231 line by short tandem repeat profiling.

\section{Transfection and generation of stable cell lines}

MDA-MB-231T cells overexpressing NME1, NME2 and Nme1 was generated using lentivirus system $\left(10^{7}-10^{9} \mathrm{TU} / \mathrm{ml}\right.$, C-Flag-SV40-eGFP-IRES-Puromycin; GeneCopoea). $5 \times 10^{4}$ cells/well were plated in $24-w e l l$ plate and allowed to grow for $24 \mathrm{hrs}$. A viral suspension $(\sim 0.5 \mathrm{ml})$ containing lentivirus $(10 \mu \mathrm{l})$, growth media (500 $\mu \mathrm{l})$ and Polybrene $(0.5 \mu \mathrm{l}-5 \mu \mathrm{g} / \mathrm{ml})$ was added to the cells and cultured overnight. Regular growth media was added next day and after 72 hrs GFP expression was visualized. Following this, Puromycin selection was performed (5-10 $\mu \mathrm{g} / \mathrm{ml})$. To obtain higher NMEs expression, GFP positive cells were FACS sorted and were maintained in Puromycin containing growth medium.

\section{Mutagenesis}

NME1 ORF purified plasmid was purchased from GeneCopoeia (EX-M0930-Lv203) along with its vector control (EX-NEG-Lv203). Mutagenesis of NME1 was performed using QuikChange II Site-Directed Mutagenesis Kit (Cat\# 200523, Agilent technologies, Santa Clara, USA) for generating P96S (F-5'-CGGGG AGACCAACTCTGCAGACTCCAAGC-3') and H118F 
(F-5'-ACAGAATCACTGCCAAATATAATGTTCCTG

CCAACTTGTATGCAGA-3') mutants. PCR conditions used for mutagenesis was $95^{\circ} \mathrm{C}-1 \mathrm{~min} ; 18$ cycles of $95^{\circ} \mathrm{C}$ $50 \mathrm{sec}, 60^{\circ} \mathrm{C}-50 \mathrm{sec}, 68^{\circ} \mathrm{C}$ for $6.5 \mathrm{~min} ; 68^{\circ} \mathrm{C}$ for $7 \mathrm{~min}$. PCR product was transfected and bacterial colonies were screened for positive clones and finally sequence verified.

\section{NDPK assay}

NDPK assay was performed as described previously [17, 64, 65]. Briefly, purified enzyme (EC 2.7.4.6, N2635-100UN, Sigma Aldrich) or lysate (preferably 10 $\mu 1)$ was added to a (preferably $990 \mu \mathrm{l}$ ) reaction mixture containing $83 \mathrm{mM}$ triethanolamine, $0.70 \mathrm{mM}$ thymidine 5'-diphosphate, $2.2 \mathrm{mM}$ adenosine 5'-triphosphate, 0.2 mM $\beta$-NADH, $1.1 \mathrm{mM}$ phospho(enol)pyruvate, $16.7 \mathrm{mM}$ magnesium chloride, $66.7 \mathrm{mM}$ potassium chloride, 10 units lactic dehydrogenase and 7 units pyruvate kinase. The reaction was mixed immediately and decrease in absorbance of NADH at $340 \mathrm{~nm}$ was then recorded for 5 min. Following this, $\Delta \mathrm{A}_{340 \mathrm{~mm}} /$ minute was calculated using the maximum linear rate for both the Test and Blank group. Units $/ \mathrm{ml} / \mathrm{mg}$ protein was calculated by the following formula:

$=[(\mathrm{DA} 340 \mathrm{~nm} / \mathrm{min}$ Test $-\mathrm{DA} 340 \mathrm{~nm} / \mathrm{min}$ Blank $)$ (Volume of assay) (dilution factor)] / [(6.22) (volume of sample $(\mathrm{ml}) \times$ concentration $\mathrm{mg} / \mathrm{ml})$ ]

\section{1 and 3-phosphohistidine immunoblotting}

Detection of phosphohistidine using 1-phosphohistidine and 3-phosphohistidine antibodies were performed per the previously reported protocol [37]. Briefly, a modified western was performed to preserve phosphohistidine by using basic $\mathrm{pH}$ buffers (8-9) and by avoiding heating in sample preparation. For whole cell lysates, $70-100 \%$ confluent MDA-MB-231T and MDAMB-435 cells in $10 \mathrm{~cm}^{2}$ dishes were rinsed twice with 5 $\mathrm{ml}$ cold TD buffer (TBS -/-, pH 8). Cells were harvested by scraping them in $2 \mathrm{X}$ sample buffer, $\mathrm{pH} 8.8(5 \mathrm{X}=10 \%$ $\mathrm{SDS}, 250 \mathrm{mM}$ Tris- $\mathrm{HCl}$, pH 8.8, 0.02\% bromophenol blue, $50 \%$ glycerol, $50 \mathrm{mM}$ EDTA, $500 \mathrm{mM}$ DTT). Harvested cells were incubated on ice, sonicated (3-5 x 5 sec bursts) and were clarified by centrifugation $(14,000 \times \mathrm{g}$ for 5-15 $\min$ at $4^{\circ} \mathrm{C}$ ). Supernatants were collected and immediately analyzed on freshly prepared Bis-Tris polyacrylamide gels with a modified, $\mathrm{pH} 8.8$ stacking gel $(5 \mathrm{ml}$ : water$2.975 \mathrm{ml}, 0.5 \mathrm{M}$ Tris-HCl pH8.8-1.250ml, $10 \%$ SDS- $50 \mu \mathrm{l}$, Acrylamide- $670 \mu 1,10 \%$ APS-50 $\mu 1$, TEMED- $5 \mu 1$ ) and $12 \%$ resolving gels $(10 \mathrm{ml}$ : water- $3.2 \mathrm{ml}$, Acrylamide- $4 \mathrm{ml}$, $1.5 \mathrm{M}$ Tris- $\mathrm{HCl} \mathrm{pH} 8.8-2.6 \mathrm{ml}, 10 \% \mathrm{SDS}-100 \mu 1,10 \%$ APS$100 \mu$ l, TEMED- 10 $\mu 1$ ). Samples were resolved at $90-100 \mathrm{~V}$ for 2-3 $\mathrm{hr}\left(4^{\circ} \mathrm{C}\right)$ in $1 \mathrm{X}$ running buffer $(1 \mathrm{~L}, \mathrm{pH} 8.5$; SDS-1g, Trizma Base-3g, glycine-14.4g, water to 1L) and Proteins were transferred to Immobilon-FL PVDF membranes at $30 \mathrm{~V}$ for $12-18 \mathrm{hr}$ at $4^{\circ} \mathrm{C}$ in Transfer Buffer: (1X 4L, $\mathrm{pH}$ 8.5, $56.7 \mathrm{~g}$ glycine, $4 \mathrm{~g}$ SDS, $12 \mathrm{~g}$ Trizma Base, 800 $\mathrm{ml} \mathrm{MeOH}$, water to $4 \mathrm{~L}$ ). Membrane was incubated for 1 $\mathrm{hr}$ at RT in Blocking Buffer (Odyssey Blocking Buffer, TBS -LICOR 927-50000). Membrane was incubated with Primary antibody (Anti-N1-Phosphohistidine-1:1000, MABS1330 or Anti-N3-Phosphohistidine 1:1000, MABS1351, Millipore) diluted in blocking buffer with $0.1 \%$ Tween-20, for $1 \mathrm{hr}$ at RT. Membrane was washed thrice for 10 min each with $0.1 \%$ TBST. Following this, membrane was incubated with secondary antibody (DyLight-680 goat anti-rabbit IgG, diluted 1: 10,000 in blocking buffer supplemented with $0.1 \%$ Tween-20 and $0.01 \%$ SDS) for $1 \mathrm{hr}$ at RT. Membrane was finally washed with $0.1 \%$ TBST thrice and visualized in Multi-application gel imaging system PXi (Syngene). For multiplexing, following 1-pHis detection, blot was incubated in $\beta$-actin antibody (1: 10,000, A5441-0.2ML, Sigma Aldrich) overnight and after washing thrice for 10 min each with $0.1 \%$ TBST, secondary antibody was added (Alexa Fluor ${ }^{\circledR}$ 568 donkey anti-mouse IgG, diluted 1: 10,000 in blocking buffer supplemented with $0.1 \%$ Tween-20 and $0.01 \%$ SDS). For total NME, the same blot was stripped (Restore Western Blot-Stripping Buffer, \#21059, Thermo Fisher Scientific Inc.) and after blocking, blot was incubated with Primary antibody (NME, sc-343, 1:1000, Santa Cruz Biotechnology) for $1 \mathrm{hr}$ at room temperature. Membrane was washed thrice for $10 \mathrm{~min}$ each with $0.1 \%$ TBST and incubated with secondary antibody (DyLight-680 goat anti-rabbit IgG, as before) for $1 \mathrm{hr}$ at RT. After washing, blot was visualized in Multi-application gel imaging system PXi (Syngene).

\section{Lysates and protein quantitation}

Both MDA-MB-231T and MDA-MB-435 cells were twice washed in $1 \mathrm{X}$ Phosphate-buffered saline. Cells were $\left(10 \mathrm{~cm}^{2}\right.$ dish) lysed in $100 \mu \mathrm{l}$ RIPA buffer $(20 \mathrm{mM}$ Tris$\mathrm{HCl}, \mathrm{pH} 8.0 ; 100 \mathrm{mM} \mathrm{NaCl} ; 10 \%$ Glycerol; $1 \%$ NP-40; $0.5 \%$ Sodium deoxycholate; $0.1 \%$ SDS; Protease Inhibitor Cocktail) added directly on cells and were incubated on ice for $10 \mathrm{~min}$. Cells were scraped and clarified by spinning at $10,000 \mathrm{rpm}$ for $10 \mathrm{~min}$ at $4^{\circ} \mathrm{C}$. supernatants were collected and protein estimation was performed by BCA analysis (Pierce ${ }^{\circledR}$ BCA Protein Assay Reagent A and B- Prod\# 23228). Lysates were frozen at $-80^{\circ} \mathrm{C}$ until use. Equal amount of protein was loaded on Any $\mathrm{KD}^{\mathrm{TM}}$ MiniPROTEAN TGX ${ }^{\mathrm{TM}}$ Gels (BIO-RAD, Cat\# 456-9033).

\section{Protein expression and purification}

Cloning, expression and purification of NME1 and mutant NME1 (P96S and H118F) were performed at Protein Production Core, Frederick National Laboratory for Cancer Research (FNL). All the constructs were His 


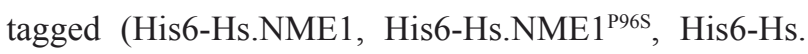
NME $1^{\mathrm{H} 118 \mathrm{~F}}$ for protein purification. To test the quality and amount of protein induction, a microscale induction was performed in $E$. coli cells using $0.5 \mathrm{mM}$ IPTG in rich media (Dynamite) or by auto-induction. All the three proteins produced more purifiable protein using Dynamite expression media. Finally, $100 \mathrm{ml}$ of $E$. coli cell cultures were induced with $0.5 \mathrm{mM}$ IPTG in rich media (Dynamite) and purified by affinity purification using immobilized metal affinity chromatography (IMAC). Affinity purification of proteins using IMAC is based on the interactions between a transition metal ion $(\mathrm{Co} 2+$, $\mathrm{Ni} 2+, \mathrm{Cu} 2+, \mathrm{Zn} 2+)$ immobilized on a matrix and specific amino acid side chains such as histidine which exhibits the strongest interaction [66]. All the purified samples were dialyzed into $50 \mathrm{mM}$ Tris, $\mathrm{pH} 8.0,150 \mathrm{mM} \mathrm{NaCl}$, $1 \mathrm{mM}$ TCEP. To test the purity of proteins, a coomassie stained $10-20 \%$ gradient SDS-PAGE gel of the partially purified proteins was run. Following this all samples were aliquoted and frozen at $-80^{\circ} \mathrm{C}$.

\section{1-phosphohistidine immunofluorescence}

Immunofluorescence for the detection of 1-phosphohistidine was performed as described previously [37]. Briefly, MDA-MB-231T and MDA-MB-435 cells were plated $\left(10^{4}\right.$ cells/well $)$ on chamber slides and allowed to grow for $24 \mathrm{hrs}$. Cells were washed with PBS ( $\mathrm{pH} 7.4$ ) and fixed in 4\% PFA for $20 \mathrm{~min}$. Cells were then washed twice with PBS ( $\mathrm{pH} 7.4$ ) and permeabilized in PBS $(\mathrm{pH}$ 9.0) containing $0.1 \%$ Triton $\mathrm{X}-100$ at $\mathrm{RT}$ for $15 \mathrm{~min}$. Cells were washed thrice in PBS ( $\mathrm{pH} 9.0)$ and blocked in $4 \%$ BSA containing $0.1 \%$ TBST, at RT for $30 \mathrm{~min}$. Cells were incubated with primary antibody (Anti-N1Phosphohistidine antibody SC1-1, \#MABS1330, dilution $1: 100$, Millipore) at RT for $90 \mathrm{~min}$ and washed thrice in $0.1 \%$ TBST for $5 \mathrm{~min}$. Cells were incubated in secondary antibody (Alexa Fluor-Sheep-anti-rabbit $568 \mathrm{~nm}$, dilution 1:2,000, in TBST containing 1\% BSA) at RT for $60 \mathrm{~min}$ in the dark. Cells were washed thrice with TBST at RT for $5 \mathrm{~min}$. To stain nuclei, chamber slides were incubated with PBS containing DAPI $(1: 5,00)$ for $10 \mathrm{~min}$ and washed thrice with PBS. Chamber slide was mounted with a coverslip using mounting media and visualized in confocal microscope under $60 \mathrm{X}$ magnification. For the detection of total NME1/2, after primary (1-pHis) incubation was over, cells were washed twice with PBS and were incubated with NME1/2 antibody (sc-465, Santa Cruz Biotechnology, 1:100) overnight in 1\% BSA in $0.1 \%$ TBST. The secondary antibodies for both NME1/2 (Alexa Fluor-Goat anti-mouse $568 \mathrm{~nm}$ ) and 1-pHis (Alexa FluorSheep-anti-rabbit $633 \mathrm{~nm}$ ) were added together.

\section{Cellular viability}

Equal numbers $(10,000$ cells/ well $)$ of MDAMB-231 (Vector, NME1, NME-2) and MDA-MB-435 (C-100 and H1-177) cells were plated in 96-well plates. Cellular viability after 24 and 48 hrs was measured using AlamarBlue dye (Thermo scientific, USA) by incubating cells with AlamarBlue dye in the growth medium (1:10) for $3 \mathrm{hrs}$. Viable cells change the color of this dye from blue (non-fluorescent) to red (fluorescent) which was quantitated at 560/590 nm (excitation/emission). Percent viability was calculated using the following formula: $\%$ Viability $=$ (Fluorescence of overexpressing cells/ Fluorescence of the vector) $\mathrm{x} 100$

\section{Boyden chamber motility assay}

Motility assays were performed as described previously [67]. Briefly, cells were trypsinized and counted using MOXI Z cell counter. Equal number of cells were plated into each upper wells of Boyden chamber $(0.1$ million/ml; $56 \mu \mathrm{l})$ in DMEM. Upper and lower chamber are separated by a coated membrane (Polyvinyl membrane $8 \mu \mathrm{m}$, coated overnight with $5 \mu \mathrm{g} / \mathrm{ml}$ of collagen type I and washed in PBS for 30'). These cells were allowed to migrate towards lower wells of the Boyden chamber containing $1 \%$ FBS $(30 \mu \mathrm{l}$, chemoattractant $)$ in a humidified chamber at $37^{\circ} \mathrm{C}$ and $5 \% \mathrm{CO}_{2}$ for $4 \mathrm{hrs}$. Nonmigrated cells were wiped off and cells that had migrated to the undersurface of the membrane were fixed and stained with Diff-Quik solutions (Dade-Behring). All the stained and migrated cells were examined microscopically. Representative areas of each well were counted to determine the number of cells that had migrated. Mean $(+/-$ SEM) number of cells migrated $(n=4)$ are plotted in the graph.

\section{Migration assay}

For 2D migration assay $2 \times 10^{5}$ cells (MDA-MB$231 \mathrm{~T}$ and MDA-MB-435) were plated per well to 6-well plates in normal growth medium. Cells were grown for 24 hours to attain $\sim 90 \%$ confluency. A horizontal line was drawn on the outside of 6-well plate to mark the scratch area. A vertical scratch was made in the center of each well using P200 pipette tip which bisects outer horizontal line. Cells were washed to remove debris and growth medium $(0.2 \%$ FBS $)$ was added to it. Specific scratch area was photographed using a phase contrast microscope $(10 \mathrm{X})$ and marked as time zero $(0 \mathrm{hrs})$. The same area was photographed after $24 \mathrm{hrs}$ and percent area open of each well was calculated using ImageJ. Percent (\%) Area Closed was calculated by subtracting area closed at $24 \mathrm{hrs}$ to area closed at $0 \mathrm{hrs}$ for each well. 


\section{In vitro histidine protein kinase assay}

Recombinant NME1 (WT) and mutant NME1 (P96S and H118F) proteins were purified as per protocol described above. Recombinant SUCLG1 and SUCLG2 proteins (Abnova, H00008801/02; GST tagged) were purchased. For phosphohistidine transfer reaction, wild type NME1 or mutant NME1 (400 ng) was added with either SUCLG1 or SUCLG2 (600 ng) to TMD buffer (20mM Tris-HCl, $\mathrm{pH} 8.8 ; 5 \mathrm{mM} \mathrm{MgCl} 2 ; 1 \mathrm{mM}$ DTT) containing ATP $(0.25 \mu \mathrm{M})$. This reaction was incubated for $30^{\prime}$ at room temperature. Reaction was stopped by adding $5 \mathrm{x}$ lysis buffer (final $2 \mathrm{x}$ ) and 1-phosphohistidine western protocol was used for the detection of N1 or N3phosphohistidine. The same blot was stripped (Restore Western Blot-Stripping Buffer, \#21059, Thermo Fisher Scientific Inc.) and processed for detection of SUCLG1/2 using anti-GST antibody (1:2000, ab19256). For detection of phosphoserine, phosphothreonine and phosphotyrosine, the reaction was stopped using $2 \mathrm{x}$ loading sample buffer and samples were heated at $95^{\circ} \mathrm{C}$ for $5 \mathrm{~min}$. Samples were resolved on Any KD ${ }^{\mathrm{TM}}$ Mini-PROTEAN TGXTM Gels and, after transfer, membranes were incubated with p-Serine (AB1606, 1:1000, Millipore), P-Threonine (AB1607, 1:1000, Millipore) or p-Tyrosine (05-321, 1:1000, Millipore) antibody. Following stripping, antiGST and NME proteins were detected. MDA-MB-231T cell lysate was used as positive control.

\section{Blue native polyacrylamide gel electrophoresis (BN PAGE)}

NativePAGETM Gels (Pre-cast NativePAGETM Novex 4-16\% (v/v) Bis-Tris, BN1002BOX) were purchased from Thermo Fisher Scientific Inc. It is based on the Blue Native Polyacrylamide Gel Electrophoresis (BN PAGE) technique, where in Coomassie G-250 was used to confers a net negative charge on proteins while maintaining the proteins in their native state (without any protein denaturation). Recombinant protein samples (WTNME1, $\mathrm{NME}^{\mathrm{P} 96 \mathrm{~S}}$ and $\mathrm{NME}^{\mathrm{H} 118 \mathrm{~F}}-8 \mu \mathrm{g}$ ) were first mixed with or without ATP $(1 \mu \mathrm{M})$ and incubated for 30 ' at room temperature. The reaction was stopped using sample buffer (final-1x) and samples were loaded on the gel. Gel was run using Dark Blue Cathode (1X) and Anode Buffer (1X) with near neutral $\mathrm{pH}(7.5)$ at $150 \mathrm{~V}$ for 1.5 hrs and $250 \mathrm{~V}$ for $30^{\prime}$ at $4{ }^{\circ} \mathrm{C}$. NativeMark ${ }^{\mathrm{TM}}$ Unstained Protein Standard was used as protein marker. Following this, gels were destained in Methanol 40\%, Acetic Acid $10 \%$ overnight. Images were taken in ChemiDoc Touch imaging system (Bio-Rad).

\section{Statistical analyses}

All experiments were repeated at least three times unless noted. For motility, migration and NDPK assays, statistical significance was calculated by a Student's $t$ test or 1-way ANOVA.

\section{Abbreviations}

NDPK- Nucleoside Diphosphate Kinase; HPKHistidine protein kinase; AWD- Abnormal Wing Discs; KSR- Kinase Suppressor of Ras

\section{Author contributions}

IK and PSS designed the experiments and wrote the manuscript. IK performed the experiments.

\section{CONFLICTS OF INTEREST}

The authors declare no conflict of interest.

\section{FUNDING}

Authors are supported by the Intramural Program of the National Cancer Institute, National Institutes of Health.

\section{REFERENCES}

1. Steeg PS, Bevilacqua G, Kopper L, Thorgeirsson UP, Talmadge JE, Liotta LA, Sobel ME. Evidence for a novel gene associated with low tumor metastatic potential. J Nat'1 Cancer Inst. 1988; 80: 200-4.

2. Leone A, Flatow U, King CR, Sandeen MA, Margulies IMK, Liotta LA, Steeg PS. Reduced tumor incidence, metastatic potential, and cytokine responsiveness of nm23transfected melanoma cells. Cell. 1991; 65: 25-35.

3. Leone A, Flatow U, VanHoutte K, Steeg PS. Transfection of human nm23-H1 into the human MDA-MB-435 breast carcinoma cell line: Effects on tumor metastatic potential, colonization, and enzymatic activity. Oncogene. 1993; 8: 2325-33.

4. Salerno M, Ouatas T, Palmieri D, Steeg PS. Inhibition of signal transduction by the nm23 metastasis suppressor: possible mechanisms. Clin Exp Metastasis. 2003; 20: 3-10.

5. Miele ME, De La Rosa A, Lee JH, Hicks DJ, Dennis JU, Steeg PS, Welch DR. Suppression of human melanoma metastasis following introduction of chromosome 6 is independent of NME1 (Nm23). Clin Exp Metastasis. 1997; 15: 259-65.

6. Tagashira H, Hamazaki K, Tanaka N, Gao C, Namba M. Reduced metastatic potential and c-myc overexpression of 
colon adenocarcinoma cells (Colon 26 line) transfected with nm23-R2/rat nucleoside diphosphate kinase alpha isoform. Int J Mol Med. 1998; 2: 65-8.

7. Miyazaki H, Fukuda M, Ishijima Y, Takagi Y, Iimura T, Negishi A, Hirayama R, Ishikawa N, Amagasa T, Kimura N. Overexpression of nm23-H2/NDP kinase B in a human oral squamous cell carcinoma cell line results in reduced metastasis, differentiated phenotype in the metastatic site, and growth factor-independent proliferative activity in culture. Clin Cancer Res. 1999; 5: 4301-7.

8. Baba H, Urano T, Okada K, Furukawa K, Nakayama E, Tanaka H, Iwasaki K, Shiku H. Two isotypes of murine nm23/nucleoside diphosphate kinase, nm23-M1 and nm23-M2, are involved in metastatic suppression of a murine melanoma line. Cancer Res. 1995; 55: 1977-81.

9. Bhujwalla ZM, Aboagye EO, Gillies RJ, Chacko VP, Mendola CE, Backer JM. Nm23-transfected MDA-MB-435 human breast carcinoma cells form tumors with altered phospholipid metabolism and $\mathrm{pH}$ : a 31P nuclear magnetic resonance study in vivo and in vitro. Magn Reson Med. 1999; 41: 897-903.

10. Parhar RS, Shi Y, Zou M, Farid NR, Ernst P, al-Sedairy ST. Effects of cytokine-mediated modulation of nm23 expression on the invasion and metastatic behavior of B16F10 melanoma cells. Int J Cancer. 1995; 60: 204-10.

11. Russell RL, Pedersen AN, Kantor J, Geisinger K, Long R, Zbieranski N, Townsend A, Shelton B, Brunner N, Kute TE. Relationship of nm23 to proteolytic factors, proliferation and motility in breast cancer tissues and cell lines. Br J Cancer. 1998; 78: 710-7.

12. Suzuki E, Ota T, Tsukuda K, Okita A, Matsuoka K, Murakami M, Doihara H, Shimizu N. nm23-H1 reduces in vitro cell migration and the liver metastatic potential of colon cancer cells by regulating myosin light chain phosphorylation. Int J Cancer. 2004; 108: 207-11.

13. Rosengard AM, Krutzsch HC, Shearn A, Biggs JR, Barker E, Margulies IM, King CR, Liotta LA, Steeg PS. Reduced Nm23/Awd protein in tumor metastasis and aberrant Drosophila development. Nature. 1989; 342: 177-80.

14. Attwood PV, Wieland T. Nucleoside diphosphate kinase as protein histidine kinase. Naunyn Schmiedebergs Arch Pharmacol. 2015; 388: 153-60.

15. Garces E, Cleland WW. Kinetic studies of yeast nucleoside diphosphate kinase. Biochemistry. 1969; 8: 633-40.

16. de la Rosa A, Williams RL, Steeg PS. Nm23/nucleoside diphosphate kinase: toward a structural and biochemical understanding of its biological functions. Bioessays. 1995; 17: 53-62.

17. Biggs J, Hersperger E, Steeg PS, Liotta LA, Shearn A. A Drosophila gene that is homologous to a mammalian gene associated with tumor metastasis codes for a nucleoside diphosphate kinase. Cell. 1990; 63: 933-40.

18. Munoz-Dorado J, Inouye S, Inouye M. Nucleoside diphosphate kinase from Myxococcus xanthus. II.
Biochemical characterization. J Biol Chem. 1990; 265: 2707-12.

19. Wallet V, Mutzel R, Troll H, Barzu O, Wurster B, Veron M, Lacombe ML. Dictyostelium nucleoside diphosphate kinase highly homologous to $\mathrm{Nm} 23$ and Awd proteins involved in mammalian tumor metastasis and Drosophila development. J Natl Cancer Inst. 1990; 82: 1199-202.

20. Gilles AM, Presecan E, Vonica A, Lascu I. Nucleoside diphosphate kinase from human erythrocytes. Structural characterization of the two polypeptide chains responsible for heterogeneity of the hexameric enzyme. J Biol Chem. 1991; 266: 8784-9.

21. Palacios F, Schweitzer JK, Boshans RL, D'SouzaSchorey C. ARF6-GTP recruits Nm23-H1 to facilitate dynamin-mediated endocytosis during adherens junctions disassembly. Nat Cell Biol. 2002; 4: 929-36.

22. Boissan M, Montagnac G, Shen Q, Griparic L, Guitton J, Romao M, Sauvonnet N, Lagache T, Lascu I, Raposo G, Desbourdes C, Schlattner U, Lacombe ML, et al. Membrane trafficking. Nucleoside diphosphate kinases fuel dynamin superfamily proteins with GTP for membrane remodeling. Science. 2014; 344: 1510-5.

23. Wagner P, Vu ND. Phosphorylation of ATP-Citrate Lyase by Nucleoside diphosphate kinase. J Biol Chem. 1995; 270 : 21758-64.

24. Crovello CS, Furie BC, Furie B. Histidine phosphorylation of P-selectin upon stimulation of human platelets: a novel pathway for activation-dependent signal transduction. Cell. 1995; 82: 279-86.

25. Cuello F, Schulze RA, Heemeyer F, Meyer HE, Lutz S, Jakobs KH, Niroomand F, Wieland T. Activation of heterotrimeric $\mathrm{G}$ proteins by a high energy phosphate transfer via nucleoside diphosphate kinase (NDPK) B and Gbeta subunits. Complex formation of NDPK B with Gbeta gamma dimers and phosphorylation of His-266 IN Gbeta. J Biol Chem. 2003; 278: 7220-6.

26. Srivastava S, Li Z, Ko K, Choudhury P, Albaqumi M, Johnson AK, Yan Y, Backer JM, Unutmaz D, Coetzee WA, Skolnik EY. Histidine phosphorylation of the potassium channel KCa3.1 by nucleoside diphosphate kinase $\mathrm{B}$ is required for activation of $\mathrm{KCa} 3.1$ and $\mathrm{CD} 4 \mathrm{~T}$ cells. Mol Cell. 2006; 24: 665-75.

27. Embark HM, Setiawan I, Poppendieck S, van de Graaf SF, Boehmer C, Palmada M, Wieder T, Gerstberger R, Cohen $\mathrm{P}$, Yun CC, Bindels RJ, Lang F. Regulation of the epithelial $\mathrm{Ca} 2+$ channel TRPV5 by the NHE regulating factor NHERF2 and the serum and glucocorticoid inducible kinase isoforms SGK1 and SGK3 expressed in Xenopus oocytes. Cell Physiol Biochem. 2004; 14: 203-12.

28. Cai X, Srivastava S, Surindran S, Li Z, Skolnik EY. Regulation of the epithelial $\mathrm{Ca}(2)(+)$ channel TRPV5 by reversible histidine phosphorylation mediated by NDPK-B and PHPT1. Mol Biol Cell. 2014; 25: 1244-50.

29. Freije JM, Blay P, MacDonald NJ, Manrow RE, Steeg PS. 
Site-directed mutation of Nm23-H1. Mutations lacking motility suppressive capacity upon transfection are deficient in histidine-dependent protein phosphotransferase pathways in vitro. J Biol Chem. 1997; 272: 5525-32.

30. Hartsough MT, Morrison DK, Salerno M, Palmieri D, Ouatas T, Mair M, Patrick J, Steeg PS. Nm23-H1 metastasis suppressor phosphorylation of kinase suppressor of Ras via a histidine protein kinase pathway. J Biol Chem. 2002; 277: 32389-99.

31. Wagner PD, Steeg PS, Vu ND. Two-component kinase like activity of Nm23 correlates with its motility suppressing activity. Proc Nat'1 Acad Sci USA. 1997; 94: 9000-5.

32. Marino N, Marshall JC, Collins JW, Zhou M, Qian Y, Veenstra T, Steeg PS. Nm23-h1 binds to gelsolin and inactivates its actin-severing capacity to promote tumor cell motility and metastasis. Cancer Res. 2013; 73: 5949-62.

33. Jung H, Seong HA, Ha H. NM23-H1 tumor suppressor and its interacting partner STRAP activate p53 function. J Biol Chem. 2007; 282: 35293-307.

34. Roymans D, Willems R, Van Blockstaele DR, Slegers H. Nucleoside diphosphate kinase (NDPK/NM23) and the waltz with multiple partners: possible consequences in tumor metastasis. Clin Exp Metastasis. 2002; 19: 465-76.

35. Carotenuto M, Pedone E, Diana D, de Antonellis P, Dzeroski S, Marino N, Navas L, Di Dato V, Scoppettuolo MN, Cimmino F, Correale S, Pirone L, Monti SM, et al. Neuroblastoma tumorigenesis is regulated through the Nm23-H1/h-Prune C-terminal interaction. Sci Rep. 2013; 3: 1351 .

36. Murakami M, Lan K, Subramanian C, Robertson ES. Epstein-Barr virus nuclear antigen 1 interacts with Nm23-H1 in lymphoblastoid cell lines and inhibits its ability to suppress cell migration. J Virol. 2005; 79: 155968.

37. Fuhs SR, Meisenhelder J, Aslanian A, Ma L, Zagorska A, Stankova M, Binnie A, Al-Obeidi F, Mauger J, Lemke G, Yates JR 3rd, Hunter T. Monoclonal 1- and 3-Phosphohistidine Antibodies: New Tools to Study Histidine Phosphorylation. Cell. 2015; 162: 198-210.

38. Morera S, Lacombe ML, Yingwu X, LeBras G, Janin J. $\mathrm{X}$-ray structure of human nucleoside diphosphate kinase $\mathrm{B}$ complexed with GDP and 2A resolution. Structure. 1995; 3: 1307-14.

39. Tepper A, Dammann H, Bominaar A, Veron $\mathrm{M}$. Investigation of the active site and the conformational stability of nucleoside diphosphate kinase by site directed mutagenesis. J Biol Chem. 1994; 269: 32175-80.

40. Kantor JD, McCormick B, Steeg PS, Zetter BR. Inhibition of cell motility after nm23 transfection of human and murine tumor cells. Cancer Res. 1993; 53: 1971-3.

41. Freije JMP, Blay P, MacDonald NJ, Manrow RE, Steeg PS. Site-directed mutation of Nm23-H1. Mutations lacking motility suppressive capacity upon transfection are deficient in histidine-dependent protein phosphotransferase pathways in vitro. J Biol Chem. 1997; 272: 5525-32.

42. Timmons L, Xu J, Hersperger G, Deng XF, Shearn A. Point mutations in awdKpn which revert the prune/Killer of prune lethal interaction affect conserved residues that are involved in nucleoside diphosphate kinase substrate binding and catalysis. J Biol Chem. 1995; 270: 23021-30.

43. Biggs J, Tripoulas N, Hersperger E, Dearolf C, Shearn A. Analysis of the lethal interaction between the prune and Killer of prune mutations of Drosophila. Genes Dev. 1988; 2: $1333-43$.

44. Chiadmi M, Morera S, Lascu I, Dumas C, Le Bras G, Veron M, Janin J. Crystal structure of the Awd nucleotide diphosphate kinase from Drosophila. Structure. 1993; 1: 283-93.

45. Wagner $\mathrm{P}, \mathrm{Vu}$ ND. Histidine to aspartate phosphotransferase activity of nm23 protein: Phosphorylation of Aldolase C on Asp 319. Biochem J. 2000; 346: 623-30.

46. Song EJ, Kim YS, Chung JY, Kim E, Chae SK, Lee KJ. Oxidative modification of nucleoside diphosphate kinase and its identification by matrix-assisted laser desorption/ ionization time-of-flight mass spectrometry. Biochemistry. 2000; 39: 10090-7.

47. Postel EH, Weiss VH, Beneken J, Kirtane A. Mutational analysis of NM23-H2/NDP kinase identifies the structural domains critical to recognition of a c-myc regulatory element. Proc Natl Acad Sci U S A. 1996; 93: 6892-7.

48. Lascu I, Deville-Bonne D, Glaser P, Veron M. Equilibrium dissociation and unfolding of nucleoside diphosphate kinase from Dictyostelium discoideum. Role of proline 100 in the stability of the hexameric enzyme. J Biol Chem. 1993; 268: 20268-75.

49. Bohl CR, Harihar S, Denning WL, Sharma R, Welch DR. Metastasis suppressors in breast cancers: mechanistic insights and clinical potential. Journal of Molecular Medicine. 2014; 92: 13-30.

50. Dykxhoorn DM. MicroRNAs and Metastasis: Little RNAs Go a Long Way. Cancer Research. 2010; 70: 6401-6.

51. Smith SC, Theodorescu D. Learning therapeutic lessons from metastasis suppressor proteins. Nature Reviews Cancer. 2009; 9: 253-64.

52. Marino N, Marshall JC, Collins JW, Zhou M, Qian YZ, Veenstra T, Steeg PS. Nm23-H1 Binds to Gelsolin and Inactivates Its Actin-Severing Capacity to Promote Tumor Cell Motility and Metastasis. Cancer Research. 2013; 73: 5949-62.

53. D'Angelo A, Garzia L, Andre A, Carotenuto P, Aglio V, Guardiola O, Arrigoni G, Cossu A, Palmieri G, Aravind L, Zollo M. Prune cAMP phosphodiesterase binds nm23-H1 and promotes cancer metastasis. Cancer Cell. 2004; 5: 13749.

54. Subramanian C, Cotter M, Robertson E. Epstein-Barr virus nuclear protein EBNA-3C interacts with the human metastatic suppressor Nm23-H1: A molecular link to cancer metastasis. Nat Medicine. 2001; 7: 350-5. 
55. Boissan M, Montagnac G, Shen QF, Griparic L, Guitton J, Romao M, Sauvonnet N, Lagache T, Lascu I, Raposo G, Desbourdes C, Schlattner U, Lacombe ML, et al. Nucleoside diphosphate kinases fuel dynamin superfamily proteins with GTP for membrane remodeling. Science. 2014; 344: 1510-5.

56. Peuchant E, Bats ML, Moranvillier I, Lepoivre M, Guitton J, Wendum D, Lacombe ML, Moreau-Gaudry F, Boissan M, Dabernat S. Metastasis suppressor NM23 limits oxidative stress in mammals by preventing activation of stress-activated protein kinases/JNKs through its nucleoside diphosphate kinase activity. Faseb Journal. 2017; 31: 153146.

57. Moreno V, Gonzalo P, Gomez-Escudero J, Pollan A, Acin-Perez R, Breckenridge M, Yanez-Mo M, Barreiro O, Orsenigo F, Kadomatsu K, Chen CS, Enriquez JA, Dejana E, et al. An EMMPRIN-gamma-catenin-Nm23 complex drives ATP production and actomyosin contractility at endothelial junctions. Journal of Cell Science. 2014; 127 : 3768-81.

58. Matthews H. Protein kinases and phosphatases that act on histidine, lysine or arginine residues in eukaryotic proteins: A possible regulator of the mitogen-activated protein kinase cascade. Pharac Ther. 1995; 67: 323-50.

59. White KA, Ruiz DG, Szpiech ZA, Strauli NB, Hernandez RD, Jacobson MP, Barber DL. Cancer-associated arginineto-histidine mutations confer a gain in $\mathrm{pH}$ sensing to mutant proteins. Sci Signal. 2017; 10.

60. Cuello F, Schulze R, Heemeyer F, Meyer H, Lutz S, Jakobs $\mathrm{K}$, Niroomand F, Wieland T. Activation of heterotrimeric $\mathrm{G}$ proteins by a high energy phosphoate transfer via nucleoside diphosphate kinase (NDPK) B and Gb subunits. J Biol Chem. 2003; 278: 7220-6.

61. Ignesti M, Barraco M, Nallamothu G, Woolworth JA, Duchi S, Gargiulo G, Cavaliere V, Hsu T. Notch signaling during development requires the function of awd, the Drosophila homolog of human metastasis suppressor gene Nm23. Bmc Biology. 2014; 12.

62. Dammai V, Adryan B, Lavenburg KR, Hsu T. Drosophila awd, the homolog of human nm23, regulates FGF receptor levels and functions synergistically with shi/dynamin during tracheal development. Genes \& Development. 2003; 17: 2812-24.

63. Palmieri D, Halverson DO, Ouatas T, Horak CE, Salerno M, Johnson J, Figg WD, Hollingshead M, Hursting S, Berrigan D, Steinberg SM, Merino MJ, Steeg PS. Medroxyprogesterone acetate elevation of Nm23-H1 metastasis suppressor expression in hormone receptornegative breast cancer. J Natl Cancer Inst. 2005; 97: 63242.

64. Timmons L, Hersperger E, Woodhouse E, Xu J, Liu LZ, Shearn A. The expression of the Drosophila awd gene during normal development and in neoplastic brain tumors caused by lgl mutations. Dev Biol. 1993; 158: 364-79.

65. Krishnan KS, Rikhy R, Rao S, Shivalkar M, Mosko M,
Narayanan R, Etter P, Estes PS, Ramaswami M. Nucleoside diphosphate kinase, a source of GTP, is required for dynamin-dependent synaptic vesicle recycling. Neuron. 2001; 30: 197-210.

66. Bornhorst JA, Falke JJ. Purification of proteins using polyhistidine affinity tags. Methods Enzymol. 2000; 326: 245-54.

67. Horak CE, Mendoza A, Vega-Valle E, Albaugh M, GraffCherry C, McDermott WG, Hua E, Merino MJ, Steinberg SM, Khanna C, Steeg PS. Nm23-H1 suppresses metastasis by inhibiting expression of the lysophosphatidic acid receptor EDG2. Cancer Res. 2007; 67: 11751-9. 